\title{
Spatial Organization of Chromatic Pathways in the Mouse Dorsal Lateral Geniculate Nucleus
}

\author{
(DDaniel J. Denman, Joshua H. Siegle, Christof Koch, R. Clay Reid, and Timothy J. Blanche \\ Allen Institute for Brain Science, Seattle, Washington 98109
}

In both dichromats and trichromats, cone opsin signals are maintained independently in cones and combined at the bipolar and retinal ganglion cell level, creating parallel color opponent pathways to the central visual system. Like other dichromats, the mouse retina expresses a short-wavelength (S) and a medium-wavelength (M) opsin, with the S-opsin shifted to peak sensitivity in the ultraviolet (UV) range. Unlike in primates, nonuniform opsin expression across the retina and coexpression in single cones creates a mostly mixed chromatic signal. Here, we describe the visuotopic and chromatic organization of spiking responses in the dorsal lateral geniculate and of the local field potentials in their recipient zone in primary visual cortex (V1). We used an immersive visual stimulus dome that allowed us to present spatiotemporally modulated UV and green luminance in any region of the visual field of an awake, head-fixed mouse. Consistent with retinal expression of opsins, we observed graded UV-to-green dominated responses from the upper to lower visual fields, with a smaller difference across azimuth. In addition, we identified a subpopulation of cells $(<10 \%)$ that exhibited spectrally opponent responses along the S-M axis. Luminance signals of each wavelength and color signals project to the middle layers of V1.

Key words: color; LGN; mouse; vision

\section{Significance Statement}

In natural environments, color information is useful for guiding behavior. How small terrestrial mammals such as mice use graded expression of cone opsins to extract visual information from their environments is not clear, even as the use of mice for studying visually guided behavior grows. In this study, we examined the color signals that the retina sends to the visual cortex via the lateral geniculate nucleus of the thalamus. We found that green dominated responses in the lower and nasal visual field and ultraviolet dominated responses in the upper visual field. We describe a subset of cells that exhibit color opponent responses.

\section{Introduction}

The mouse visual system, like most mammalian visual systems, is dichromatic. As in many small terrestrial mammals and unlike in primates (Roorda and Williams, 1999), in mice two opsins are expressed in a spatially nonuniform manner such that a shortwavelength $(\mathrm{S})$ opsin dominates the ventral retina and a middlewavelength (M) opsin dominates the dorsal retina (Applebury et al., 2000; Wang et al., 2011). The central retina contains an "opsin transition zone" (Chang et al., 2013), where opsin expression transitions from $\mathrm{S}$ to $\mathrm{M}$. In addition, the S-opsin, often called the blue opsin, is

Received May 30, 2016; revised Nov. 4, 2016; accepted Nov. 9, 2016.

Author contributions: D.J.D., C.K., R.C.R., and T.J.B. designed research; D.J.D. and J.H.S. performed research; D.J.D. analyzed data; D.J.D., C.K., R.C.R., and T.J.B. wrote the paper.

This work was supported by the Allen Institute for Brain Science. We thank J. Neitz, J. Kuchenbecker, J. Borseth, and N. Orlova for design and support of the stimulus environment; S. Durand, D. Williams, and the In Vivo Sciences Department for experimental support; and Allen Institute founders Paul G. Allen and Jody Allen for their vision, encouragement, and support.

T.J.B. is the founder and president of White Matter LLC, the company that produces the electrophysiology recording system used in this work. The remaining authors declare no competing financial interests.

T.J.B.'s present address: Redwood Center for Theoretical Neuroscience, University of California, Berkeley, Berkeley, CA.

Correspondence should be addressed to Daniel J. Denman, Allen Institute for Brain Science, 615 Westlake Ave. N, Seattle, WA 98109. E-mail: danield@alleninstitute.org.

DOI:10.1523/JNEUROSCI.1742-16.2016

Copyright $\odot 2017$ the authors $\quad 0270-6474 / 17 / 371102-15 \$ 15.00 / 0$ shifted in sensitivity toward the ultraviolet (UV) region of the light spectrum (Jacobs et al., 1991). This shift reduces the amount of spectral overlap between the $\mathrm{M}$ - and S-opsins and changes the area of overlap to the tail of the M-opsin, in the $<400 \mathrm{~nm}$ range (Lyubarsky et al., 1999; Jacobs et al., 2007). This organization differs from the well described organization of the color systems in trichromats and other dichromats: spectrally and spatially overlapping separable channels that create several color opponent pathways ( $\mathrm{S}-\mathrm{M}$ in dichromats, $\mathrm{S}-(\mathrm{L}+\mathrm{M})$ and $\mathrm{L}-\mathrm{M}$ in trichromats). Furthermore, in some regions of the mouse retina, many $\mathrm{M}$-cones cones express both opsins (Baden et al., 2013), conflating wavelength-specific information at the earliest-stage visual transduction.

Given these unusual features of cone opsin expression, it is not clear how the mouse visual system uses its spectral sensitivity. One hypothesis is the optimal sampling of luminance in the environment, with a strong UV source (the sun) in the upper visual field and many sources of green reflectance (foliage) in the lower visual field (Baden et al., 2013). This hypothesis assumes a predominant viewing angle and the projection of the world through the eye onto the retina (Dräger and Olsen, 1981; Sterratt et al., 2013); how the retinal mosaic samples visual space in an intact animal depends on eye, head, and body movements. Because rodent eye movements can be disconjugate and may maintain a 
A

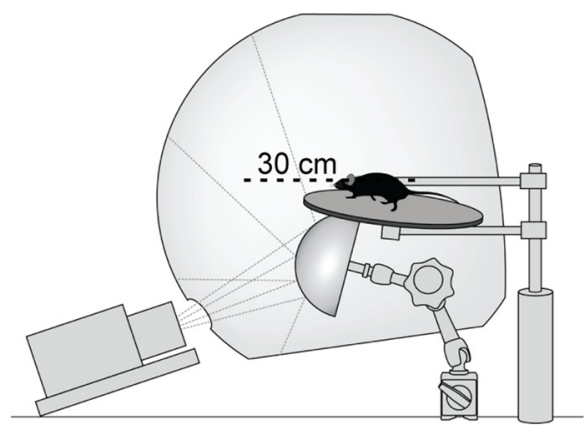

B

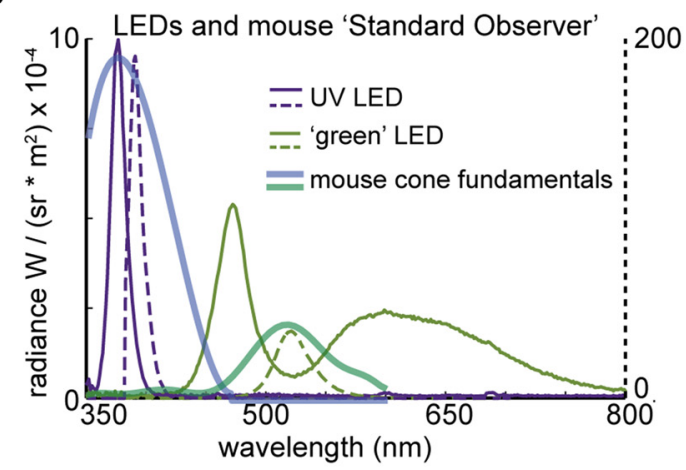

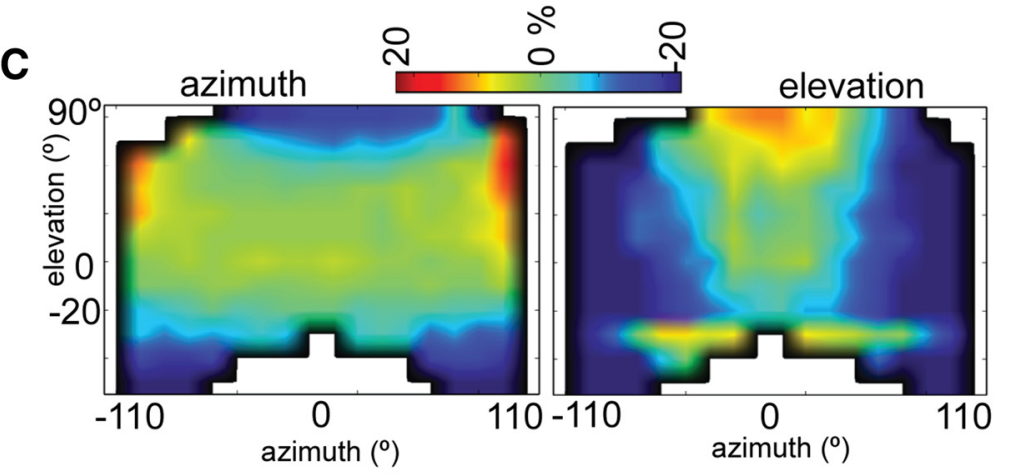

D

E
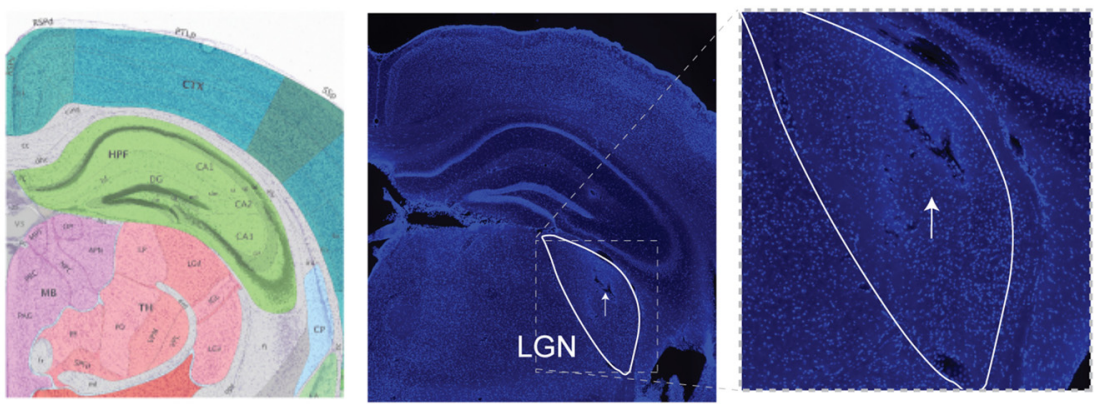

Figure 1. Visual stimulation system. $A$, Schematic of the immersive visual stimulation dome. Mouse eye position is at the center of the dome spherical coordinate frame. $\boldsymbol{B}$, Spectral properties of the projector. Spectral distributions of radiance for each LED, UV and green. Mouse "cone fundamentals" are based on electroretinogram sensitivities (Lyubarsky et al., 1999; arbitrary scale). Two projectors with different LED radiance ranges (left and right axes) and spectra are shown as solid and dashed lines; the projector with dashed-line spectra was used for chromatic substitution experiments. C, Measured accuracy of spatial warping using a fisheye warp. The variance from expected linear size is plotted as a percentage for both azimuth (left) and elevation (right). $\boldsymbol{D}$, Radiance linearity of UV LED, green LED, and total radiance. $\boldsymbol{E}$, Histological verification of dLGN probe placement. A corresponding reference section from the Allen Coronal Reference Atlas is shown at left at the same scale as the middle image. The arrows indicate the hole left by probe insertion. Nuclei are stained with DAPI.

field of view that is not in front of the animal, but above (Wallace et al., 2013), how retinal coordinates translate to visual coordinates may not be straightforward from first principles.

In addition to optimal sampling of luminance, it is possible that mice have a color opponent pathway for color discrimination. There is behavioral evidence that mice have access to wavelength information (Jacobs et al., 2004). In addition, pure S-cones can be found across the mouse retina (Haverkamp et al., 2005; Wang et al., 2011), allowing for the possibility of true M-S opponency, especially in the superior retina, where $\mathrm{M}$-cones express little S-opsin. Physiological evidence from electroretinograms (Jacobs et al., 2007), bipolar cells (Breuninger et al., 2011; Li and DeVries, 2006), and ganglion cells (Chang et al., 2013; Baden et al., 2016) indicate the presence of color opponent signals in the retina.

Little is known, however, about the cell-type-specific projections or synaptic specificity of wavelength-specific retinal ganglion cells (RGCs). Because of this, color processing in the mouse thalamocortical visual pathway, starting with dorsal lateral geniculate nucleus
(dLGN) and primary visual cortex (V1), is not fully understood. In V1, cells show a range of UV and green sensitivity, although the visuotopic organization of UV- and green-preferring cells does not appear to match the retinotopic dorsal-ventral gradient of opsin expression and there is scant evidence for the color opponent responses that may subserve color discrimination (Tan et al., 2015). Here, we used electrophysiological responses of dLGN neurons to assess the chromatic organization of the mouse central visual pathway. We mapped wavelength-specific and spectrally opponent responses across the visual field, finding a nonuniform distribution of chromatic responses across space, with UV dominating the upper visual field, a color transition zone in the $0-40^{\circ}$ elevation range, and spectrally opponent responses across the retina.

\section{Materials and Methods}

Surgery and animal preparation. All surgeries and experimental procedures were approved by the Allen Institute for Brain Science Institu- 

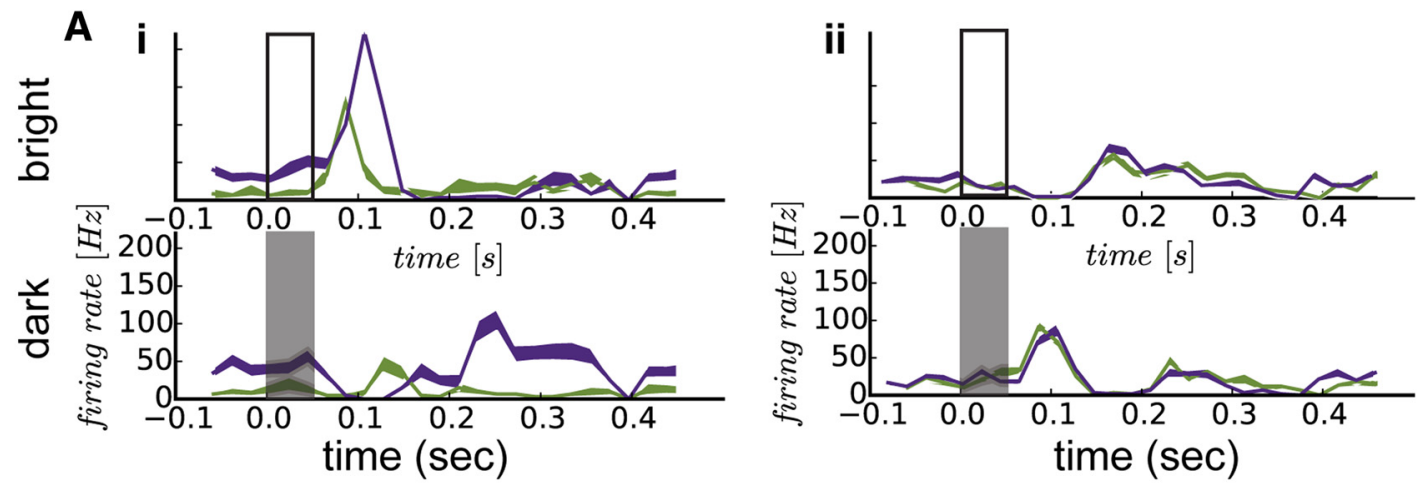

B
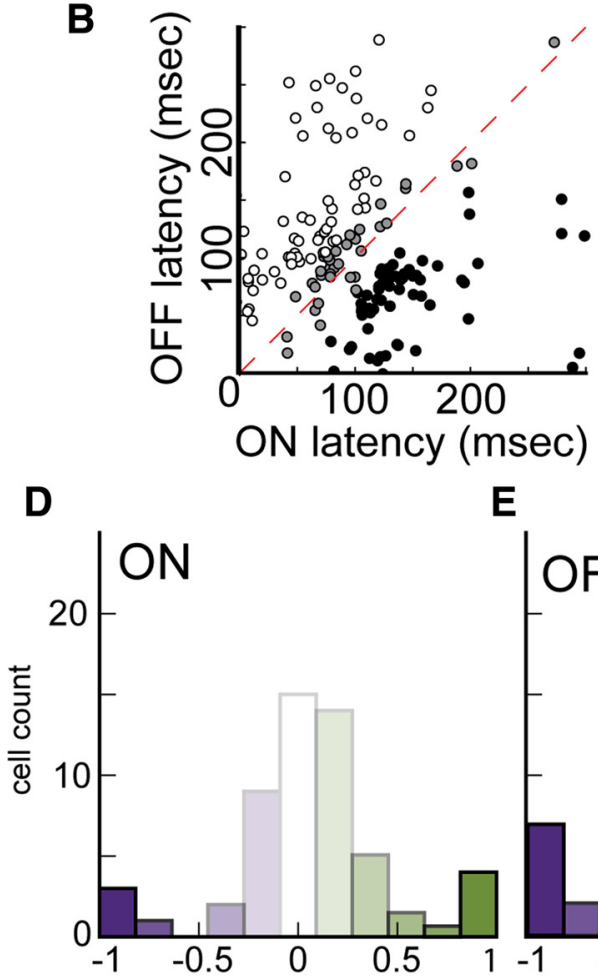

UV

E
C

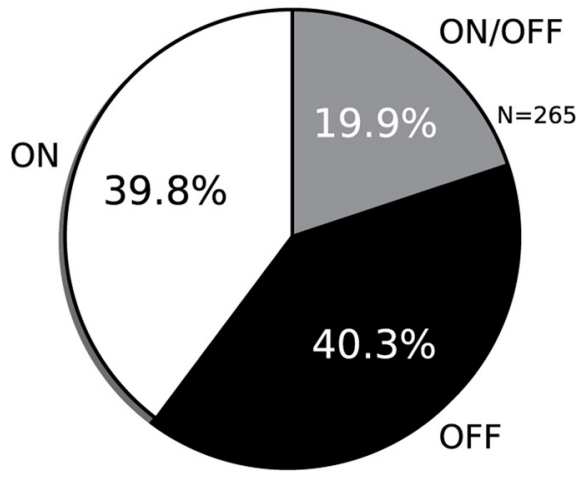

$\mathbf{F}$
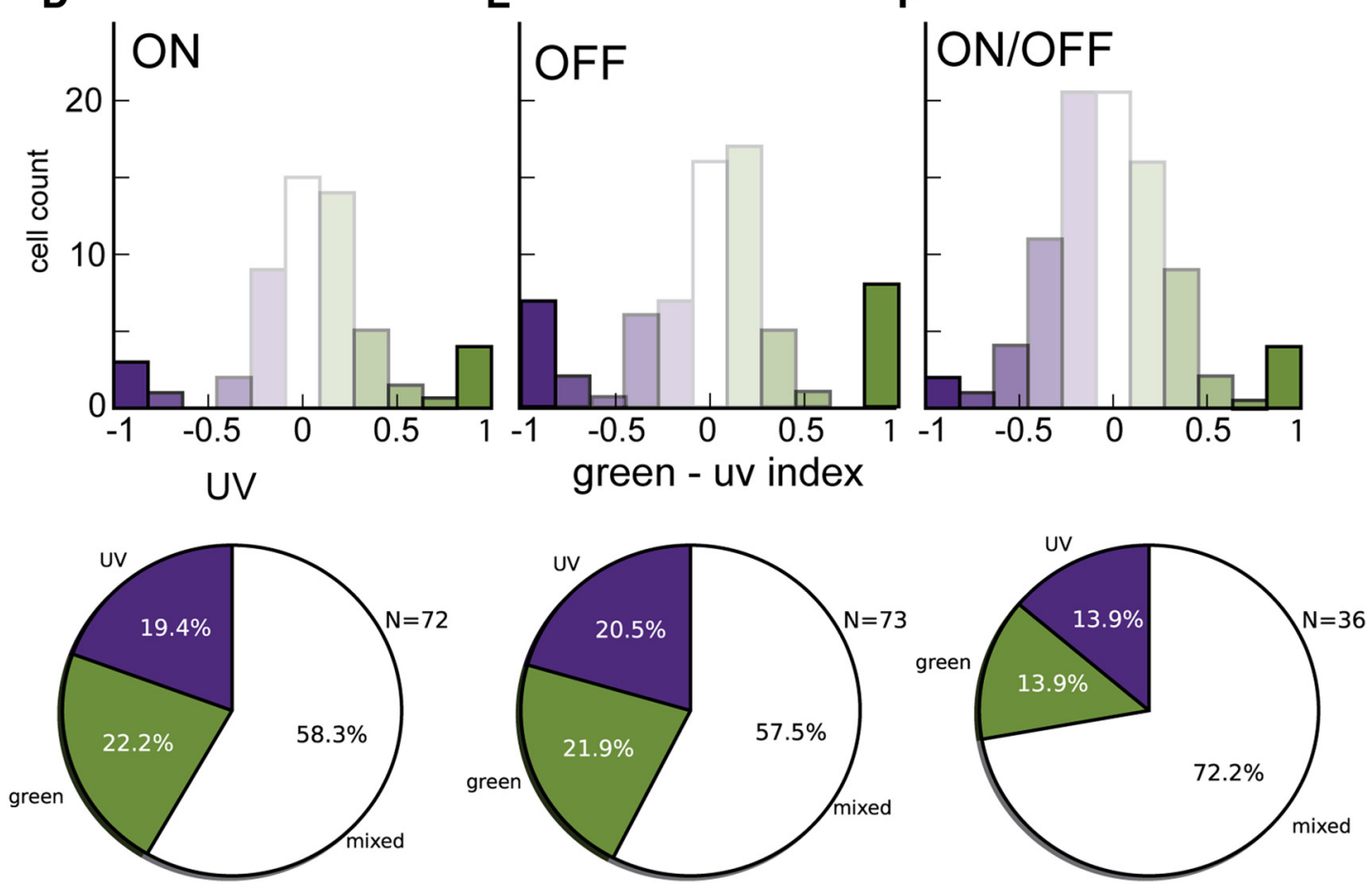

Figure 2. UV and green responses in mouse dLGN. $A$, Example responses of two single units to $50 \mathrm{~ms}$ full-field luminance changes. Ai, Example 0 N neuron that responds to the onset of bright flash (top) and the offset of a dark flash (bottom) for both UV and green luminance changes. Aii, Example OFF neuron that responds to the onset of a dark flash (bottom) and the offset of a bright flash (top). Line thickness depicts \pm SEM. $B$, Classification of each cell's response latencies to bright and dark flashes. Luminance class was determined by comparing latencies of bright versus dark flashes to identify each cell as $\mathrm{ON}$ (white), $\mathrm{OFF}$ (black), or ON/OFF (gray). C, Summary of classification results from B. D-F, Classification of each cell's chromatic response. For each cell, the relative amplitude of the correct sign responses ( $D$ : bright ON, $E$ : dark OFF, F: maximum response for ON/OFF) was used to calculate a GUVi; full distributions (top) and pie chart summaries for color classes from the above distributions (bottom).

tional Animal Care and Use Committee. Male C57BL/6 mice (RRID: IMSR_JAX:000664) between the ages of 8 and 30 weeks were used.

An initial surgery was performed to attach a head post to the skull that contained a 5-mm-diameter circular opening, which was positioned such that the anterior edge was just anterior to bregma and the bregma-lambda plane was parallel to the head post. After this surgery, the exposed skull was covered with Metabond and Kwik-Sil and the animal was allowed to recover for at least $7 \mathrm{~d}$ before habituation to the experimental apparatus. 
A
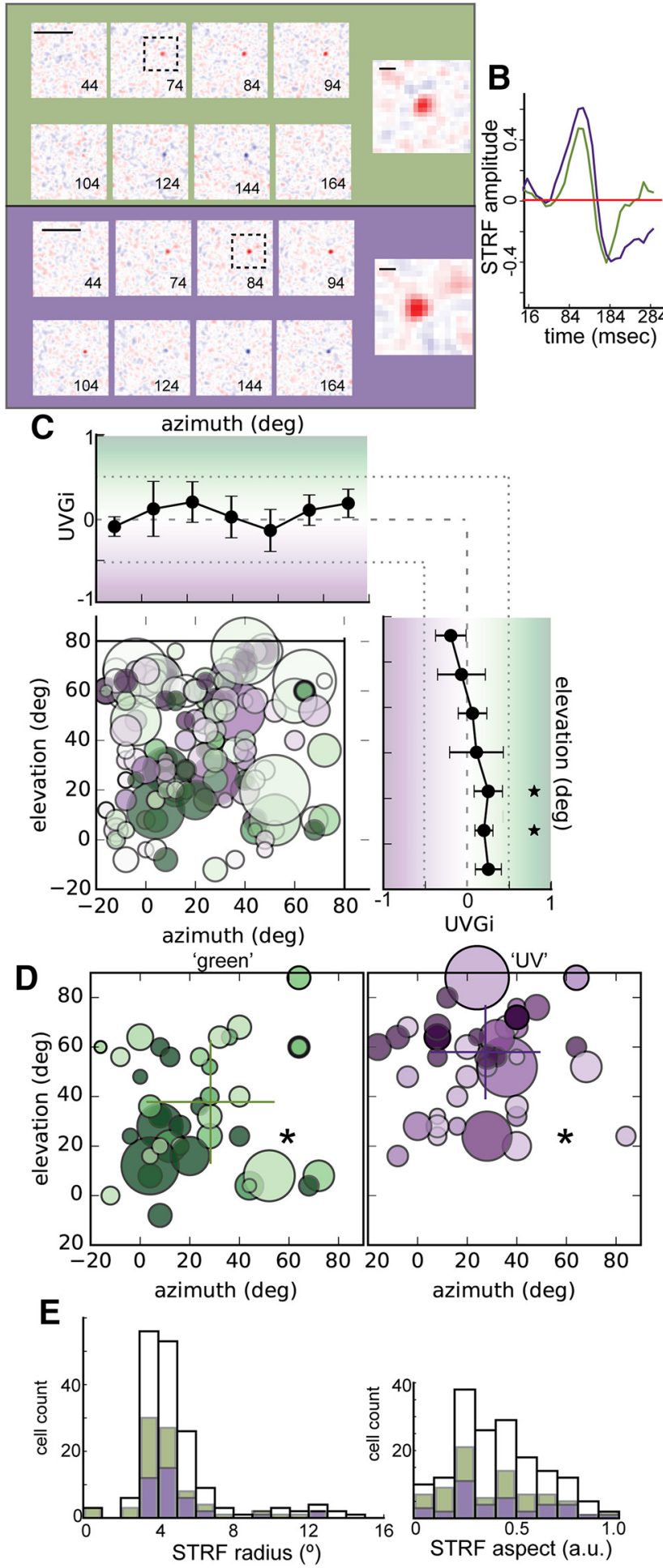

Figure 3. Spatial organization of UV and green responses. $\boldsymbol{A}$, Example spatiotemporal receptive field for estimating visuotopic coordinates. Monochromatic spatial receptive fields are shown for green (top) and UV (bottom). The spike-triggered average at several intervals (44-164 ms) are shown at left (scale bar, $50^{\circ}$ ); insets show spatial zoom of the receptive field at the peak response, as indicated by the dashed boxes (scale bar, $10^{\circ}$ ). $\boldsymbol{B}$, Impulse response functions for the example shown in $\boldsymbol{A}$. $\boldsymbol{C}$, All spatial receptive fields. Each cell is plotted as a circle with a radius determined by the mean radius of a 2D Gaussian fit of the peak spatial receptive field as follows: $\left(\sigma_{x}+\sigma_{y}\right) / 2$; color is determined by GUVi from Figure 2. Average GUVi across azimuth (above) and elevation (right) are plotted in $10^{\circ}$ bins $\left({ }^{*} p<0.05\right)$. D, Same as $C$ but showing only spatial arrangement of green (left) and UV (right) as classified by GUVi in Figure 2, D-F. Approximate gaze location is indicated with asterisk. Mean and SD of receptive field elevation and azimuth parameters are overlaid. $\boldsymbol{E}$, No difference in spatial receptive field size (left) or aspect ratio (right) among UV, green, or mixed cells (white).
Habituation to the experimental apparatus was performed over at least three sessions of increasing duration. For each session, the animal was handled after removal from the home cage and placed in the head-fixing apparatus inside the visual stimulation dome (see below). The animal was allowed to run freely on a disc and some or all of the visual stimulus battery was shown during these sessions. Habituation sessions were initially $15 \mathrm{~min}$ and were extended each day until the animal was comfortable in the apparatus for $2 \mathrm{~h}$.

On the day of recording, the animal was anesthetized for a craniotomy and insertion of an electrical reference screw. Anesthesia was induced with $5 \%$ inhaled isoflurane and maintained at at least $2 \%$; the animal's temperature was maintained at $37^{\circ} \mathrm{C}$ using a thermocoupleregulated heating system. The protective KwikSil was removed and the layer of Metabond peeled away to expose the skull. The reference screw and attached wire were inserted as far from the recording site as possible contralateral to the recording site, $\sim 100 \mu \mathrm{m}$ posterior to bregma and approximately over the motor cortex. For most recordings, two craniotomies were made, one burr hole over V1 and a second, larger, craniotomy anterior to V1 for insertion in to dLGN. Coordinates for each were measured relative to bregma; for dLGN, $-3 \mathrm{RC},-2.1 \mathrm{ML}$ was used and $-4 \mathrm{RC},-2.5$ ML were used for V1. These dLGN coordinates account for a slight angle in the approach of the dLGN electrode, which was not normal to the stereotactic coordinate system to allow both manipulators to fit above the mouse skull but out of the mouse's field of view. Large surface blood vessels visible through the skull were avoided. Each mouse underwent a single recording session.

Visual stimulation. Stimuli were displayed on the inner surface of a custom-designed spherical dome enclosure (Fig. 1A) constructed from a clear, 24-inch-diameter acrylic sphere (California Quality Plastics). The inside of the sphere was coated with a custom UVreflective paint with reflection that was spectrally flat from $350-600 \mathrm{~nm}$ but had $50 \%$ absorbance to reduce interference caused by internal reflections (Twilight Laboratory). The animal was placed on a horizontal disc suspended near the center of the sphere, head fixed such that it could run freely, and positioned with the right eye at the center of the sphere. This created a spherical coordinate system with the viewing eye at the origin. Based on previous measurements (Dräger, 1981; Sterratt et al., 2013), the optical axis projects to $22^{\circ}$ in elevation and $60^{\circ}$ in azimuth in the dome coordinate system. Stimuli were produced at 60 $\mathrm{Hz}$ by a custom digital light processing projector (DLP; DLi Innovations) with LED sources. The DLP was placed outside of the enclosure and projected through a small opening in the dome onto a silver-coated aluminum mirror (Wagner Collaborative Metal Works) suspended beneath the mouse platform. Two versions of this custom projector were used. The first contained a UV LED centered at $360 \mathrm{~nm}$ 
and a white source that contained a mixture of blue and green wavelengths (Fig. 1B). The second had an LED centered at $380 \mathrm{~nm}$ and one on $525 \mathrm{~nm}$. The mean retinal fluxes for the first projector were $9.79 \times 10^{8}$ for green and $2.22 \times 10^{8}$ for UV stimuli; for the second projector, retinal flux was $1.66 \times 10^{9}$ and $2.31 \times 10^{9}$ quanta/s/deg ${ }^{2}$, respectively. No projector LED was perfectly cone isolating; the relative excitation effectiveness of each cone for each LED was calculated based on the spectral sensitivities of mouse ERG cone b-waves (Lyubarsky et al., 1999) and correcting for the preretinal (Henriksson et al., 2010) and photopigment screening. For the first projector, the green LED stimulation of the $\mathrm{M}$-opsin was $9 \times$ more effective than for the S-opsin; the UV LED was $4 \times$ more effective for the S-opsin than for the M-opsin. For the second projector the green LED stimulation of the $\mathrm{M}$-opsin was $3 \times$ more effective; the UV LED was $>100 \times$ more effective for the S-opsin. Both projectors produced similar results for monochromatic stimuli and monochromatic data collected with each were combined. The second generated brighter stimuli and allowed for simultaneous modulation of each source in the mouse photopic range, so it was used exclusively for color exchange experiments (see below).

The dome enclosure allowed us to present visual stimuli across the visual field, covering $200^{\circ}$ in azimuth and $100^{\circ}$ in elevation. Reflection of the projector's image off of a spherical surface created spatial distortions that required correction. A fisheye warp mesh for our system was generated using the meshmapper utility (http://paulbourke.net/dome/meshmapper/). This warp was generated empirically by projecting a spherical grid onto the dome surface and manually adjusting parameters to minimize distortions in the grid. The resulting mesh allowed stimuli to be displayed isomorphically independently of the position on the dome (Fig. 1C). All stimuli were warped with this mesh before being projected onto the spherical mirror. Because this was a novel, custom stimulation system, the luminance linearity was verified. After a manual gamma correction, the system had a linear relationship between radiance (taken at across the spectrum) and contrast (Fig. 1D).

Visual stimuli were generated on a PC using custom-written software based on the PsychoPy (http://www.psychopy.org; RRID:SCR_006571) and DimStim (http://dimstim.github.io) platforms. Stimuli consisted of full-field luminance changes, spatiotemporal dense white noise, or drifting sinusoidal gratings. Monochromatic full-field luminance changes were made by modulating one LED source while the other was off. The background was set to the mean luminance for the modulating LED and stepped to either minimum (dark) or maximum (bright) luminance. For flashed stimuli, luminance steps were $50 \mathrm{~ms}$ in duration. For colorexchange stimuli, full-field changes in UV and green luminance were uncoupled from each other. Both LEDs were set to mean luminance at the start. Each flash contained a "set" and a "test" color. The set color was $70 \%$ luminance ( $40 \%$ contrast) of one LED; each test color was chosen from a sweep through luminance from minimum $(-100 \%$ contrast, dark) to maximum (100\% contrast, bright) of the other LED. During color exchange, flash duration was $1 \mathrm{~s}$ and the order of the test color presentation was randomized. Spatiotemporal noise was a $64 \times 64$ matrix of $5^{\circ}$ squares modulated at $20-30 \mathrm{~Hz}$. The full extent of this matrix extended well beyond the hemispheric mirror such that the effectively used matrix was $40 \times 22$ (azimuth $\times$ elevation). Each block in the matrix was either $100 \%$ contrast bright or dark and the luminance of each was modulated independently of all other blocks in both space and time. Drifting gratings were full field, presented at $3 \mathrm{~Hz}, 0.1 \mathrm{cycles} /{ }^{\circ}$, four orientations $\left(0^{\circ}, 45^{\circ}, 90^{\circ}, 135^{\circ}\right)$, and variable contrast. Data from all orientations were combined for contrast response functions (CRFs).

Electrophysiology. Electrophysiological data were acquired using highdensity planar silicon electrode arrays (Neuropixels probes; IMEC; Lopez et al., 2016). Arrays contained 120 electrodes spanning $1.28 \mathrm{~mm}$ with an intersite spacing of $\sim 31 \mu \mathrm{m}$. Broadband $(0.1-7.5 \mathrm{kHz})$ data were acquired and stored at a $25 \mathrm{kHz}$ sampling rate (eCube; White Matter). For each experiment, two separate electrode arrays were mounted on manual manipulators so that the position of each probe could be adjusted independently. First, one probe was lowered into dLGN. Full-field luminance changes were used as an aid in locating visually responsive thalamic neurons; the probes were lowered at $\sim 500 \mu \mathrm{m} / \mathrm{min}$ until timelocked visually evoked responses were observed. After this, the probe was lowered at $\sim 100 \mu \mathrm{m} / \mathrm{min}$ until several lower channels did not show time-locked visual responses. Visually evoked responses were continuous and spanned 150-900 $\mu \mathrm{m}$ on the probe; subcortical electrode placement was verified using post hoc histology (Fig. 1E). After placement of the subcortical probe, a second array was placed in V1. This array was inserted normal to the cortical surface at a rate of $\sim 100 \mu \mathrm{m} / \mathrm{min}$ following the piercing of the dura mater. Both arrays were left untouched for a period of at least $60 \mathrm{~min}$ before data acquisition began. All recordings were from the left hemisphere.

Data analysis. Raw data and Python (RRID:SCR_008394) Jupyter analysis notebooks are available on GitHub (see Notes). Raw data are in the Neurodata Without Borders format (Teeters et al., 2015; http://www.nwb.org/); all postspike sorting analysis and figures can be reproduced using these Jupyter notebooks.

Spike sorting was performed on data from across all stimulus condition within a single probe insertion using the spyKING CIRCUS package (Yger et al., 2016). Full details of the algorithm and implementation are available elsewhere (http://spyking-circus.readthedocs.org/). Briefly, data were filtered $(500-10000 \mathrm{~Hz})$, whitened, and spike events were identified and isolated. A parallelized Rodriguez-Laio clustering (Rodriguez and Laio, 2014) was performed on a subset of the data and the mean waveforms of the resulting clusters were used as templates for a fitting step. The resulting data were inspected manually and refined using the graphical interface of the phy package (http://phy.readthedocs.org/). Clusters were split manually and combined based primarily on interspike interval distribution shape and drift of waveform principle component values over the course of the recording.

Most calculations were based on average peristimulus time histograms (PSTHs) calculated over repeated presentations of the same stimulus. Unless otherwise noted, the peak of the PSTH was used to measure amplitude and latency of response.

A green-UV index (GUVi) was used as a metric for chromatic preference when comparing the responses of single units with separate monochromatic stimuli. GUVi was defined as follows:

$$
\frac{R_{\mathrm{Green}}-R_{\mathrm{UV}}}{R_{\mathrm{Green}}+R_{\mathrm{UV}}}
$$

where $R_{\text {Green }}$ and $R_{\mathrm{UV}}$ are the response to green and UV stimuli, respectively. The GUVi ranges from +1 , indicating a pure green response, to -1 (a pure UV response), with 0 indicating equal response to UV and green.

A sustained-transient index ( $\mathrm{STi}$ ) was used as a metric for the sustainedness of the responses to 1-s-long full-field luminance changes. STi was defined as follows:

$$
\frac{R_{\text {peak }}-R_{\text {mean }}}{R_{\text {peak }}+R_{\text {mean }}}
$$

where $R_{\text {peak }}$ is taken from the maximum value in the initial $250 \mathrm{~ms}$ of a response and $R_{\text {mean }}$ is the mean firing rate over the entire response. An STi close to 1 indicates very transient responses and close to zero a very sustained response with no early peak.

Receptive fields were calculated by reverse correlating each spike train with the white noise stimulus (Jones and Palmer, 1987). Averages were calculated at $10 \mathrm{~ms}$ intervals over at least $500 \mathrm{~ms}$. The center pixel of the receptive field was chosen as the maximum deviation from noise, positive or negative, across both space and time. The temporal impulse response was taken from this pixel and the spatial receptive field was the full spatial receptive field at the peak of this impulse response. Spatial receptive fields were fit with an oriented 2D Gaussian as follows:

$$
\begin{aligned}
& f(x, y)=O \\
& \quad+A e^{-\left(\frac{\cos (\theta)^{2}}{2 \sigma_{x}^{2}}+\frac{\sin (\theta)^{2}}{2 \sigma_{y}^{2}}\right)\left(x-x_{0}\right)^{2}+2\left(\frac{-\sin (2 \theta)}{4 \sigma_{x}^{2}}+\frac{\sin (2 \theta)}{4 \sigma_{y}^{2}}\right)\left(x-x_{0}\right)\left(y-y_{0}\right)+\left(\frac{\sin (\theta)^{2}}{2 \sigma_{x}^{2}}+\frac{\cos (\theta)^{2}}{2 \sigma_{y}^{2}}\right)\left(y-y_{0}\right)^{2}}
\end{aligned}
$$

where $O$ is an offset, $A$ is an amplitude scaling factor, $\sigma_{y}$ the widths of the Gaussian along the minor and major axes in each direction and $\theta$ is the orientation. The center point $\left(x_{0}, y_{0}\right)$, of each fit was chosen beforehand 
A
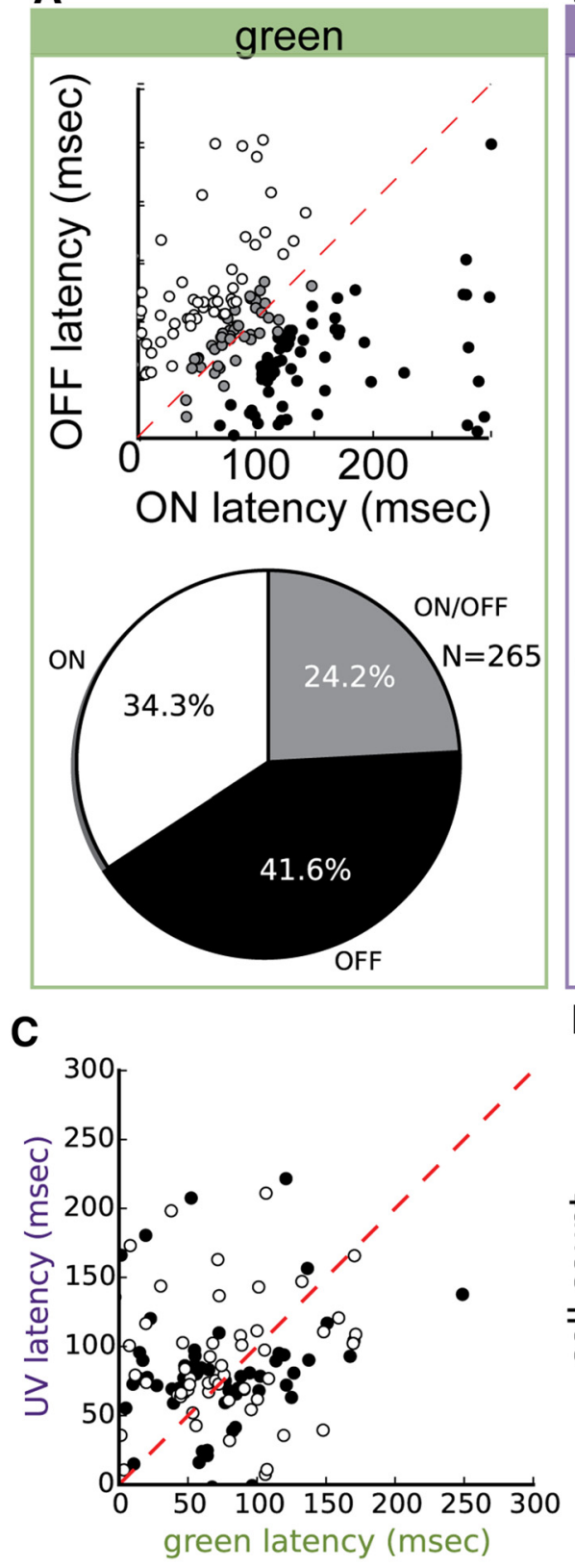

B
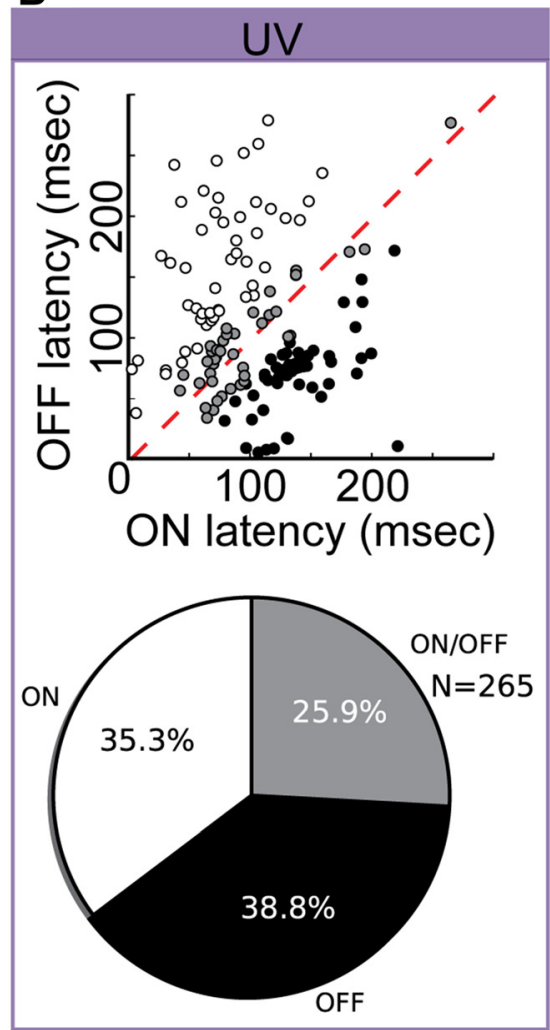

D

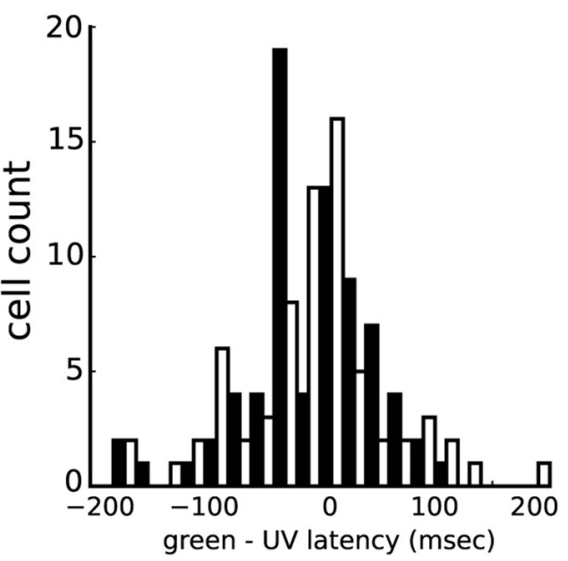

Figure 4. Temporal differences between UV and green responses. $\boldsymbol{A}, \boldsymbol{B}$, Scatter plots (top) of peak latency for bright and dark stimuli similar to Figure $2 B$ but plotted separately for green $(\boldsymbol{A})$ and UV $(\boldsymbol{B})$ luminance changes. The resulting classification is shown below for each color. C, Scatter plot of the difference between green and UV latency for each cell's correct sign luminance change (bright ON, dark OFF). D, Histogram of latency differences (green minus UV) for ON (white bars) and OFF (black bars).

and held constant during the fit process. Aspect ratio for each receptive field was calculated as the ratio of $\sigma_{\mathrm{x}}$ and $\sigma_{\mathrm{y}}$, with the larger major-axis width in always used in the denominator.

One-dimensional current source densities were computed using the open-source Python implementation of the inverse current source density (CSD) methods (Pettersen et al., 2006). Briefly, unfiltered local field potentials were trial averaged to generate evoked potentials; a linear subarray of channels was selected from the recorded to data. CSDs were computed using the standard CSD method and converted to current density using an assumed conductivity of $(0.3 \mathrm{~S} / \mathrm{m})$. Unless otherwise noted, tests for statistical significance were Welch's $t$ test.

\section{Results}

We developed an immersive visual stimulation dome capable of generating UV and green stimuli simultaneously, each with arbitrary spatio- temporal patterns across most of the mouse visual field (Fig. 1; see Materials and Methods). All experiments were performed in this immersive dome environment on awake, headfixed mice ( $n=12$ male mice, C57BL/6, RRID: IMSR_JAX:000664). Raw data and Jupyter analysis notebooks are available on GitHub (see Notes).

\section{$\mathrm{UV}$ and green responses in the mouse dLGN}

We first sought to establish the relative strength and frequency of wavelengthspecific responses in the mouse dLGN. We used the responses to brief, highcontrast full-field changes in luminance of either UV or green light. This stimulus allowed us to drive cones that provide input effectively to a given dLGN cell regardless of the retinotopic location of the receptive field; it evoked vigorous responses in most dLGN neurons (examples are shown in Fig. 2A). To classify each cell into a luminance group (ON, OFF, or ON/OFF), we measured the relative latency to peak response after luminance increments (bright) or decrements (dark; Fig. 2B). We chose latency to response (Carcieri et al., 2003) as the measure for classification because stimulus offset often overlapped with the onset response, confounding measurement of the peak amplitude. We classified as ON cells those that had a faster latency to peak response to increments in luminance than to decrements in luminance (Fig. 2B, white circles); conversely, OFF cells responded faster to decrements in luminance (Fig. 2B, black circles). Cells with latencies in which increments and decrements were not different by $>25$ ms were classified as ON/OFF. Proportions were balanced between $\mathrm{ON}$ and $\mathrm{OFF}$ (39.8\% and $40.3 \%$, respectively; Fig. 2C) in our dataset. Notably, some cells were classified differently based on green flashes and UV flashes. This suggested that, for some cells, the sign of luminance response was different for different opsins, a hypothesis that we will examine directly below (see Figs. 5 and 6).

We then used the UV and green responses to the sign-matched luminance change (increment for ON cells, decrement for OFF cells, and the stimulus that evoked the highest rate for ON/OFF cells) to evaluate the relative contribution of UV and green opsins to each dLGN cell. For each cell, we computed a GUVi ranging from 1 for a purely green-responsive cell, 0 for an equally UVand green-responsive cell, to -1 for a purely UV-responsive cell (see Materials and Methods). The distributions of GUVi for ON (Fig. 2D), OFF (Fig. 2E), and ON/OFF (Fig. 2F) cells all contained a large, broad peak centered at 0 , with specific chromatic populations near the ends of the distribution. Each distribution of GUVi was multimodal. Based on this distribution, we used GUVi to further divide each luminance group into UV, green, or 
"luminance" (threshold GUVi: \pm 0.3 ). The relative frequencies of each group are shown in Figure 2, D-F (ON: 19.4\% UV, 22.2\% green, $58.3 \%$ luminance; OFF: $20.5 \%$ UV, $21.9 \%$ green, $57.5 \%$ luminance, ON/OFF: $13.9 \mathrm{UV}, 13.9 \%$ green, $72.2 \%$ luminance).

\section{Spatial organization of UV and green cells}

To assess the spatial organization of chromatic responses, for a subset of cells we measured UV and green spatiotemporal receptive fields (STRFs) independently using a monochromatic (UV or green) binary white-noise stimulus with $5^{\circ}$ squares presented at $20-30 \mathrm{~Hz}$ (see Materials and Methods). An STRF for each cell was calculated by performing a spike-triggered average of the stimulus with that cell's spike train (example cell; Fig. $3 A, B$; Jones and Palmer, 1987). Spatial receptive fields were calculated in $10 \mathrm{~ms}$ bins and the peak spatial receptive field was determined from the time delay that evoked the strongest response (Fig. 3B). This peak spatial receptive field was fit with a $2 \mathrm{D}$ Gaussian and the resulting fit parameters were used to determine the center of each cell's receptive field in visuotopic coordinates. Based on the sign of the impulse response, the population of cells for which we recovered an STRF consisted of 80 ON cells and 58 OFF cells (based on the peak of the STRF impulse response). Receptive field centers spanned from -12.3 to $74^{\circ}$ in azimuth and -10 to $84^{\circ}$ in elevation. For cells with STRFs that were well fit by a 2D Gaussian classification with reverse correlation corresponded well with classification from flashes, with all but one cell having the same class.

The receptive field of location of each cell is plotted in Figure 3C. For each neuron for which we could recover an STRF (138/ 272 ), we used the fit parameters (2D Gaussian, radius, and center) to plot a circle in visual space; the color of the circle was determined by the GUVi from full-field flashed stimuli (Fig. 2). Cells classified as "mixed" ( $-0.3 \geq \mathrm{GUVi} \geq 0.3)$ spanned much of the visual field. On average, lower and more central parts of visual space had more green- than UV-responsive cells. Averaging the mean GUVi across elevation showed a significant shift from green to UV (Fig. $3 C$, right; ${ }^{*} p<0.05$, one-sample $t$ test, mean $=0$ ); a similar projection across azimuth showed no difference except for a slight UV bias in the far temporal visual field (Fig. 3C, top). Removing mixed chromatic cells and examining UV (GUVi $<-0.3)$ and green (GUVi $>0.3)$ cells independently (Fig. 3D) revealed a more striking difference between UV and green cells; this difference between UV and green receptive field center locations was statistically significant (UV: $25.5 \pm 3.6$, $52.5 \pm 3.2$; green: $24.4 \pm, 3.6,35.1 \pm 3.7$; azimuth $p=0.88$, elevation $p=0.0003, t$ test, plotted on Fig. $3 D$ ). UV cells were more numerous in the upper and temporal visual field; green cells were concentrated in the lower and nasal visual field.

Fitting each STRF also allowed us to evaluate other properties such as receptive field size and aspect ratio. Variation in receptive field size can be seen in the size of the markers in Figure 3C; qualitatively, it was not immediately obvious that receptive field size correlated with chromatic preference or visuotopic location. For chromatic preference, this was borne out quantitatively, as receptive field size was not statistically different for cells of any GUVi class (Fig. $3 E$; green: $4.3 \pm 2.2$, UV: $4.9 \pm 2.1 ; p=0.14$ ), nor was aspect ratio (Fig. $3 E ; p>0.05$ ). The distribution of phase parameters from these fits showed peaks at $\pi / 2$ and $-\pi / 2$, indicating a bias for vertical orientation tuning, but this orientation bias was unrelated to luminance preference.

In summary, we observed UV, green, and mixed STRFs of similar size across much of visual space. Green receptive fields were concentrated in the lower and nasal visual field, UV receptive fields in the
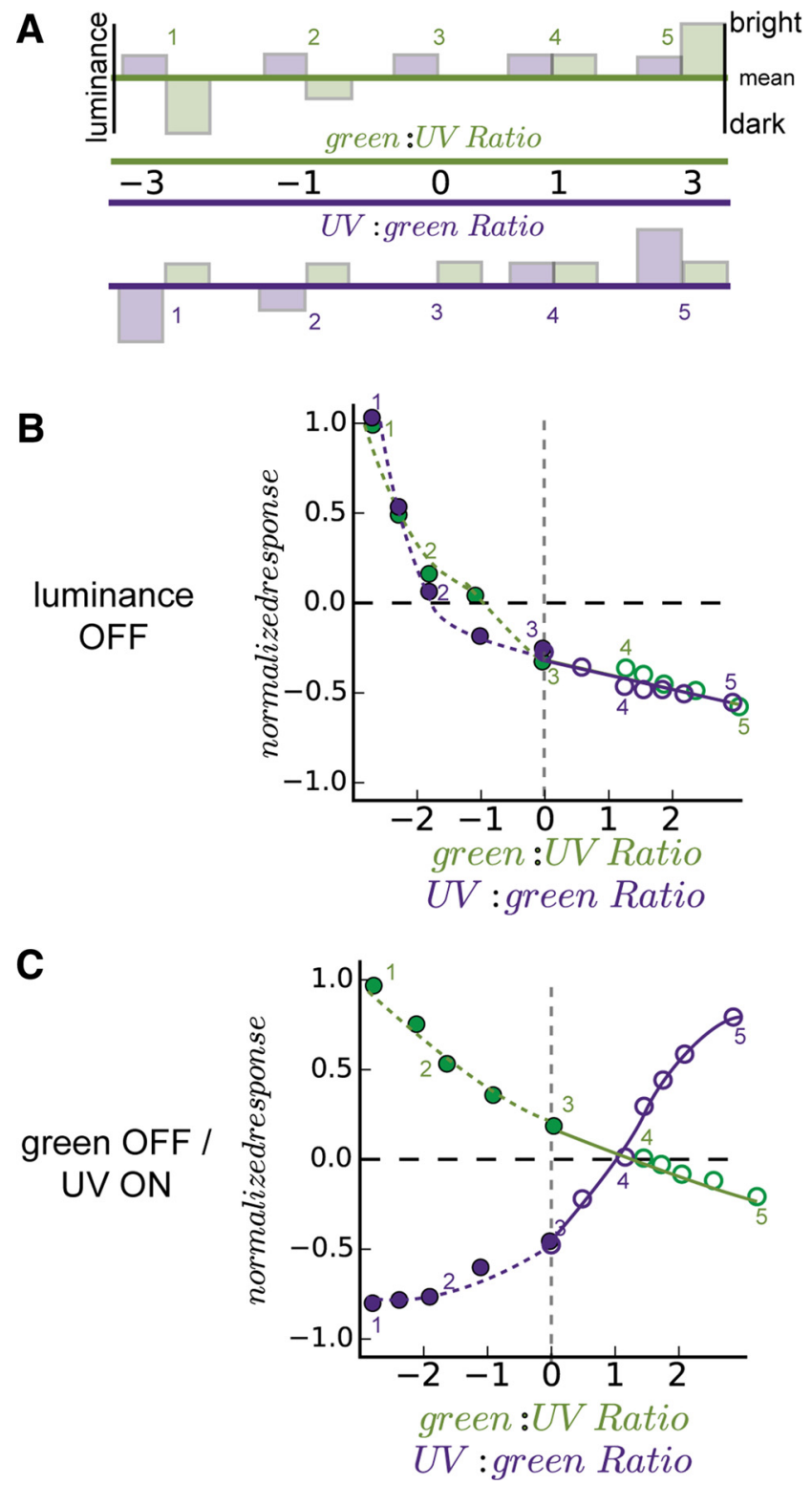

Figure 5. UV- green color exchange stimulus and hypothetical responses. $\boldsymbol{A}$, Schematic showing stimulus conditions (top). Each stimulus contained a simultaneous $1 \mathrm{~s}$ step in UV and green luminance. One LED was always stepped to a $40 \%$ increment and the other LED color change could vary, creating ratios from -2.5 to 2.5 . $\boldsymbol{B}$. Hypothetical response to the above stimuli of an OFF cell that sums luminance linearly independently of wavelength. Responses are highest to luminance decrements, are similar for UV and green, and the null point is negative. C, Hypothetical green-OFF/UV-ON cell that displays color opponency. Responses are highest for green decrements and UV increments; the responses to each color diverge and the null point is positive.

upper and temporal visual field. Notably, an area of overlapping mixed, green, and UV receptive fields, a color transition zone, covered the range of $0-40^{\circ}$ in elevation.

\section{Temporal differences between UV and green}

In addition to the difference in the visuotopic organization of green and UV responses, we investigated differences in the temporal response properties to UV and green stimuli. We first revisited the latency measurements used to classify the luminance responses. The luminance classification above was based on the latency to peak from the color stimulus that produced the highest-amplitude response (Fig. 2B); examining the latency to UV (Fig. $4 A$ ) and green flashes 

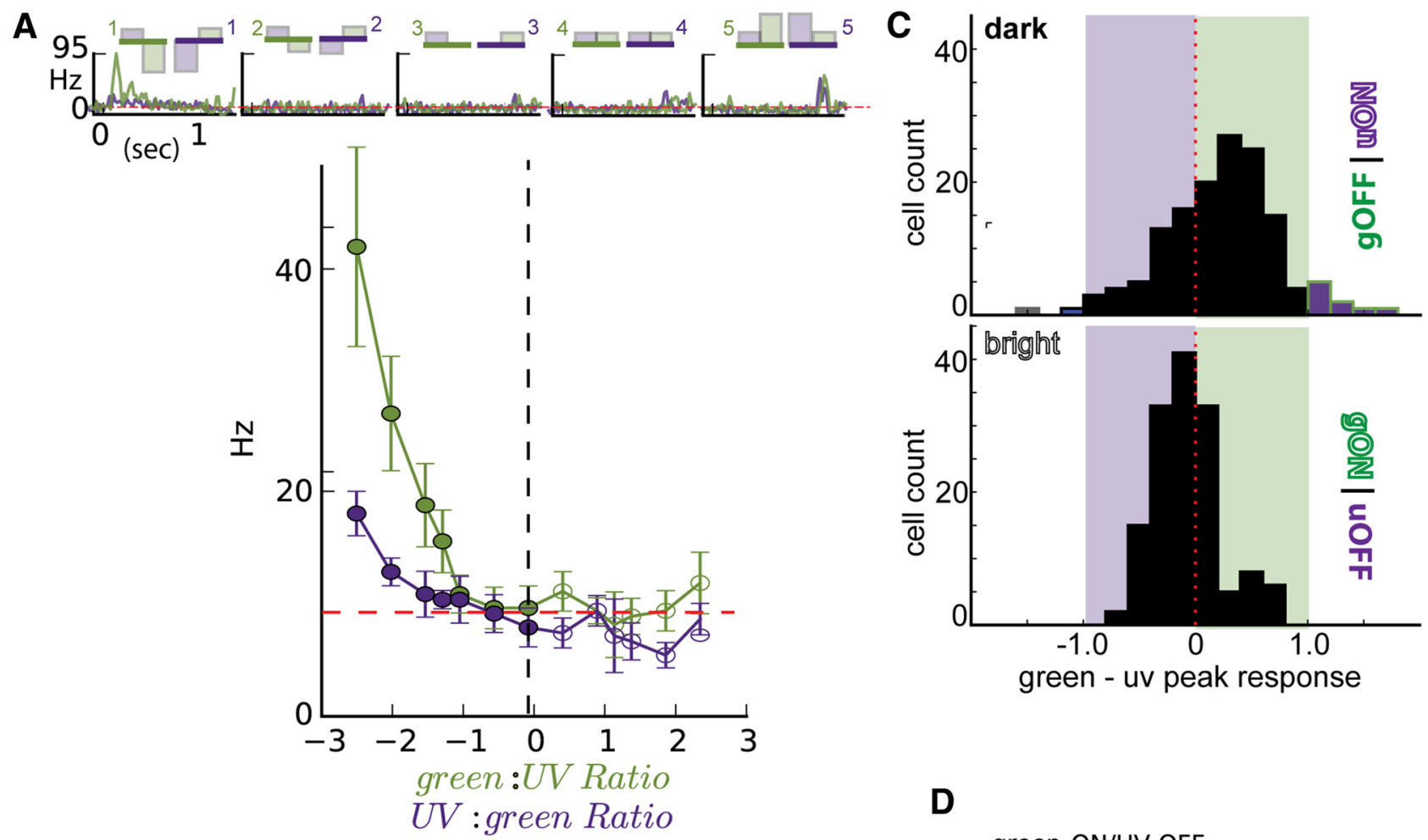

B
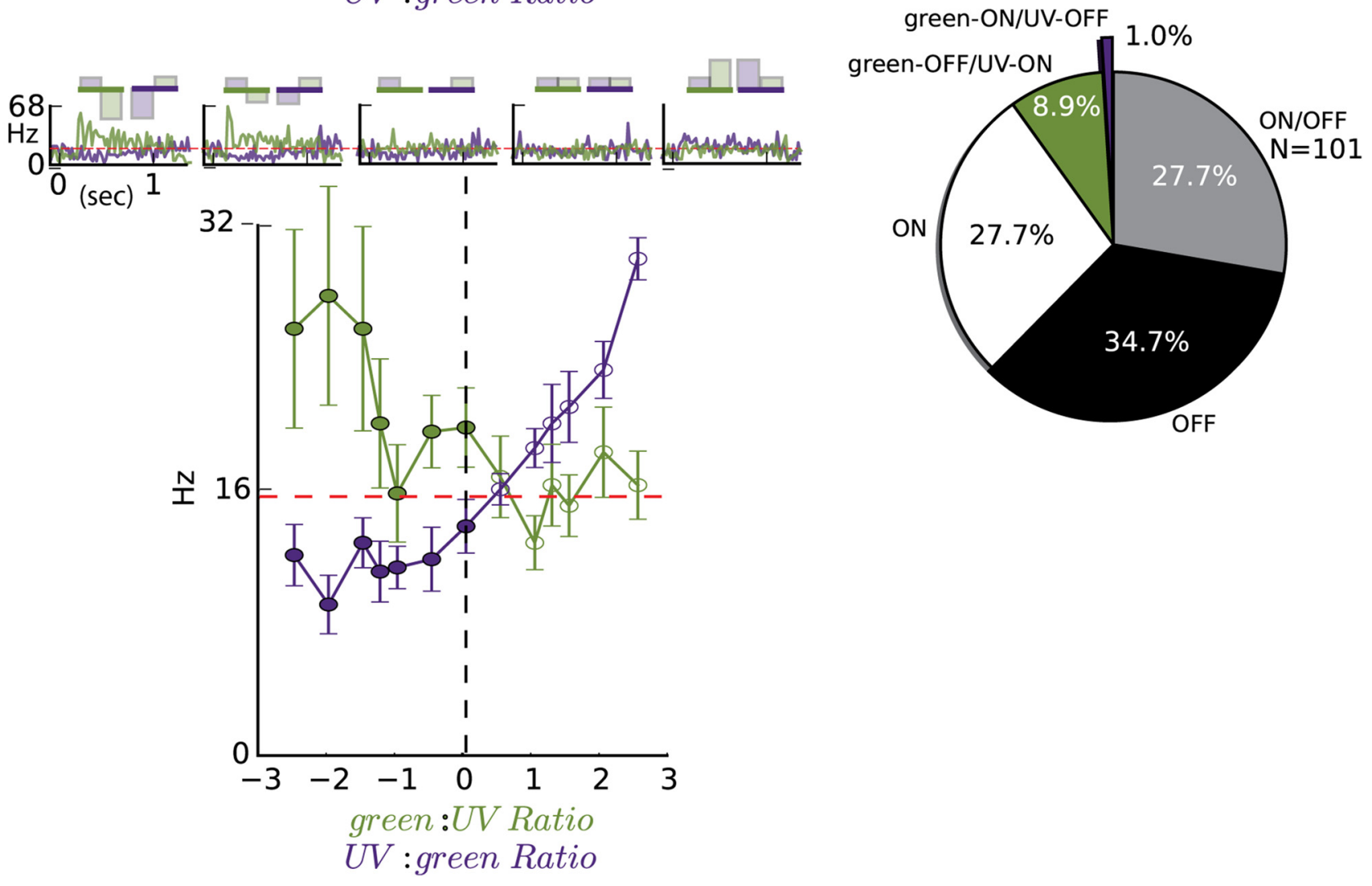

Figure 6. Identifying color opponent cells using UV-green color exchange. A, Example OFF-type unit that sums luminance contrast linearly to both UV and green decrements. Trial-averaged responses to various UV-to-green ratios are shown above; line color in each plot corresponds to the colored number above each plot. The baseline firing rate is plotted with a red dashed line on each plot. Bottom, Mean firing rate in the first $100 \mathrm{~ms}$ of response to each color exchange stimulus is shown as a function of UV-to-green and green-to-UV ratio. Red horizontal dashed line indicates baseline firing rate; black vertical dashed line at zero where UV-only and green-only increments are presented. Error bars indicate SEM. $\boldsymbol{B}$, Example unit showing color opponent green-0FF/UV-ON response; plotting conventions are the same as in $\boldsymbol{A}$. $\boldsymbol{C}$, Comparison of the normalized response strength of $\mathrm{UV}$ and green responses to the strongest stimuli. Top, Difference between green-0FF (stimulus 1, top of $\boldsymbol{A}$ ) and UV-OFF (stimulus 1, top of $\boldsymbol{B}$ ). Bottom, Difference between green-0N (stimulus 5, bottom of $\boldsymbol{A}$ ) and UV-ON (stimulus 5 , bottom of $\boldsymbol{B}$ ). $\boldsymbol{D}$, Proportions of each response type observed: luminance ON, luminance OFF, green-OFF/UV-ON, and green-ON/UV-OFF. 
(Fig. 4B) separately mostly preserved this classification for OFF cells (green only, $41.6 \%$, best $40.4 \%$, UV only $38.8 \%$ ) or ON cells (green only, $34.3 \%$, best $39.8 \%$, UV only $35.3 \%$ ).

There was tendency for UV responses to be slower than green responses (Fig. 4C,D). Subtracting UV from green latency (latency to ON stimuli for ON cells, latency to OFF stimuli for OFF cells) showed a large fraction of cells had nearly identical latencies. However, more cells had longer UV latency than green latency (above line in Fig. $4 C$; below zero in Fig. 4D). The median difference between $\mathrm{UV}$ and green latency was very similar for ON $(27.3 \mathrm{~ms})$ and OFF cells ( $24.8 \mathrm{~ms} ; p>0.05)$. Although we made efforts to ensure that the luminance of each color channel was matched to the sensitivity of each opsin (Fig. 1B), we cannot rule out latency differences due to differences in the strength of opsin activation. We will revisit the issue of temporal differences when examining the propagation of color responses from dLGN to V1 (see Fig. 10).

Spectral opponency as assessed by color exchange

Two of the preceding observations, differences in luminance classification from latency between colors (Fig. 2) and a zone containing a mixture of separate UV and green units (Fig. 3) motivated us to test directly for color opponent responses along the short-middle opsin (UV-green) color axis. To identify color opponent responses, we used a full-field heterochromatic exchange stimulus (Lee et al., 1989; Shapley and Hawken, 2002) to search efficiently for color opponent responses in the mouse dLGN.

The protocol, referred to as color exchange (Fig. 5A), contained simultaneous steps of UV and green luminance $1 \mathrm{~s}$ in duration (from a background of mean UV + green). Each stimulus contained a $40 \%$ increment of one color paired with a variable increment or decrement of the other color. This created varying ratios of UV to green opsin activation and allowed the identification of the null point where green and UV summation cancel each other. This null point allowed us to quantify how each unit combines opsin signals. The responses of a hypothetical OFF neuron, excited equally by UV and green, is illustrated in middle panel of Figure $5 B$. This hypothetical OFF cell had the highest responses to negative ratios (more dark than bright, indicated as condition \#1); the responses were the same regardless of the color of the increments and decrements (green and purple lines). A null response was observed when an increment of either color is paired with an equal decrement (condition \#2). A hypothetical color opponent cell would have very different responses to this color exchange protocol; this type of cell is illustrated in Figure $5 C$. For this green-OFF/UV-ON cell, the response depends on which color is decremented, with positive responses to green decrements and suppression to UV decrements. The null response is seen at positive values (in this case, at 1.0).

The majority (103/114) of cells summed luminance similarly to the hypothetical responses illustrated in Figure $5 B$ (e.g., the OFF luminance cell in Fig. 6A). The distribution of differences between UV and green responses (normalized responses to stimuli 1 and 5 in Fig. 5A) showed that most did so in a quasilinear fashion (Fig. 6C, between -1.0 and 1.0), with some in the population weighing green more heavily (Fig. $6 C, 0.0<$ peak $<1.0$ ). These "luminance" cells had a null response when the sign of green luminance change was opposed by a UV luminance change of the opposite sign (Fig. $6 C$, peak $\sim 0$ ).

A subset of cells $(11 / 114)$ showed striking differences from this behavior (Fig. 6C, cells $>1.0$ ). For these cells (Fig. 6B), the null response was not found when UV and green had the opposite sign, but rather when they had same sign, similar to Figure $5 C$. Accordingly, these cells also had opposite responses to UV and
A
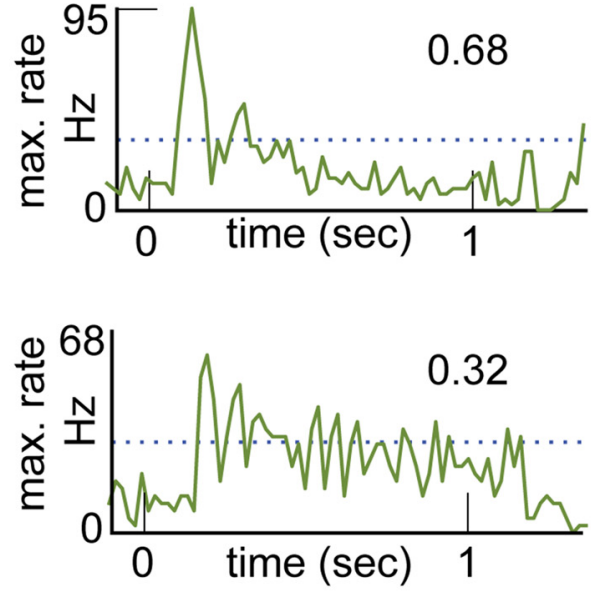

B

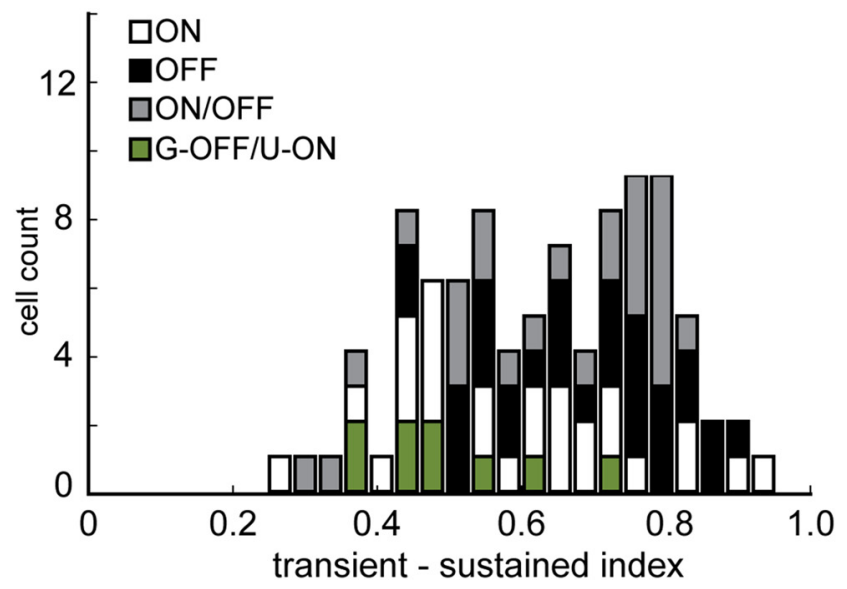

Figure 7. Transience of luminance and color opponent cells. $A$, Example PSTHs from transient (top; 0FF cell, same cell as in Fig. 5B) and sustained (bottom; green-OFF/UV-ON, same cell as in Fig. 50 neurons; inset: STi for each example neuron. The mean over the duration of the response is indicated by the dashed line for each cell. $\boldsymbol{B}$, Distribution of STi values for each cell in the population. Data are displayed as stacked histograms such that bar height shows the distribution of the total population and segments indicate the frequency for each cell type.

green: 10/11 increased firing rate to green-OFF and UV-ON, with the remaining cell increasing its firing rate to green-ON and UVOFF. Although these "color opponent" cells were rare $(\sim 10 \%$; Fig. $6 E$ ), we further quantified the temporal properties, spatial organization, and contrast sensitivities for comparison with color opponent cells in other species.

\section{Temporal properties of color opponent cells}

First, we compared the latency of these color opponent cells with luminance changes. For decrements of green luminance (paired with a small increment in UV luminance), the latency to peak response of green-OFF/UV-ON opponent cells (109.3 $\pm 42.5 \mathrm{~ms})$ was the same as luminance OFF cells $(102.5 \pm 54.7 ; p=0.66)$. For the opposite luminance change, increments in UV, the majority of green-OFF/UV-ON did not produce a response that reached significance, indicating that the green-OFF may be stronger than the UV-ON on its own. For those that did produce a significant response, the mean latency $(98.2 \pm 42.5 \mathrm{~ms})$ was no different from that of ON cells $(97 \pm 52.3 ; p=0.99)$.

Color opponent cells in the primate visual thalamus, both red-green and blue-yellow cells, were more sustained than ach- 
A
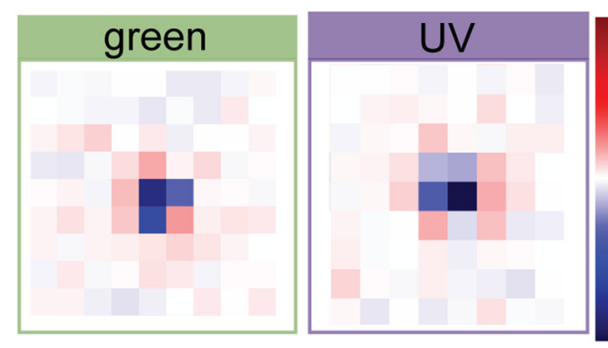

$-0.3$

B

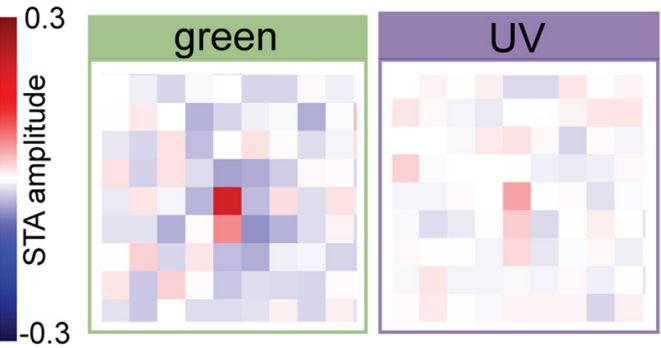

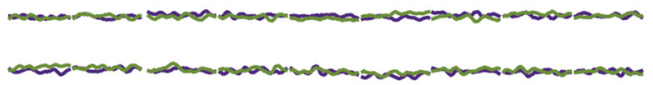
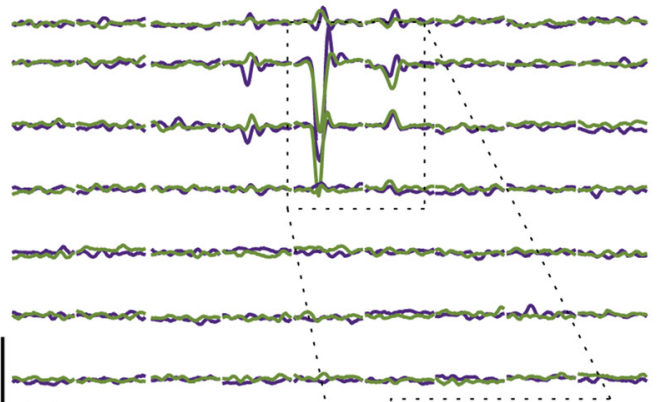

$200 \mathrm{msec}$

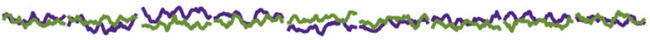

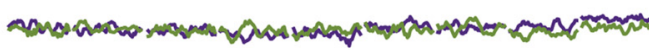

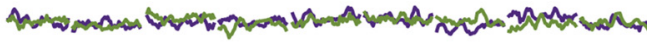

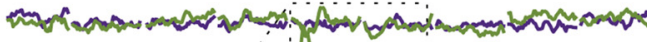

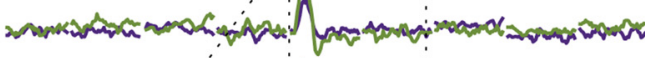

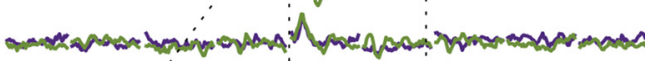

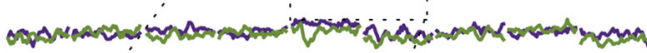

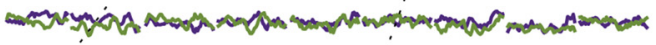

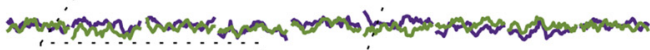

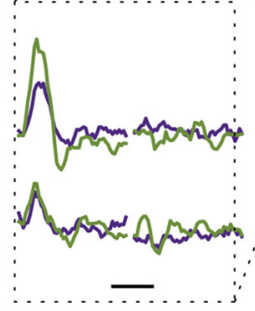

C

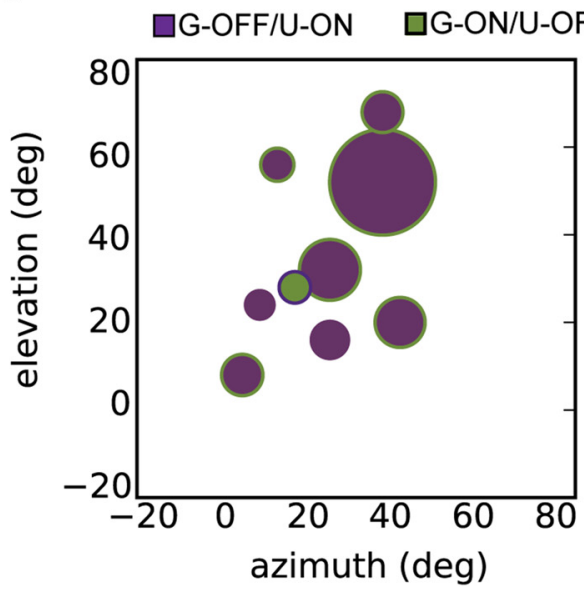

D

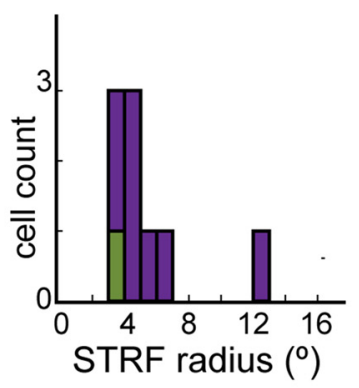

E

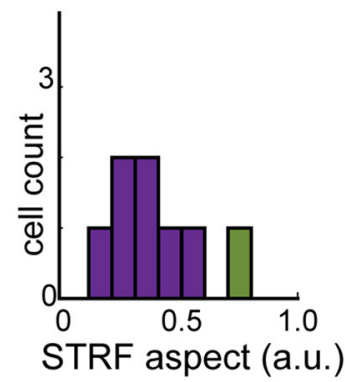

Figure 8. Spatiotemporal properties of color opponent cells. $A, B$, Example spatiotemporal receptive fields from color opponent cells. The center of the maximum spatial receptive field, centered on the same point in space, is shown for both UV and green stimuli (above). Impulse responses (below) correspond to the pixels shown above. $A$, Example green-0FF/UV-ON, impulse response scale bar, 0.4 , time scale bar, 0.2 s. B, Single UV-0N/green-OFF cell, Impulse response scale bar, 0.2 . C, Retinotopic organization of color opponent receptive field locations. $\boldsymbol{D}$, Receptive field size of color opponent cells (cf. Fig. 3E). $E$, Receptive field aspect ratio of color opponent cells (cf. Fig. 3E).

romatic magnocellular cells (Reid and Shapley, 2002). We measured a sustained-tranisent index (STi) (see Materials and Methods) from the full-field luminance changes used during the color-exchange protocol (Fig. 7A). ON, OFF, and ON/OFF luminance cells, as classified by the color exchange stimulus in Figure $6 C$, all had a bimodal distribution of STi indicating sustained and transient populations (Fig. $7 B$, Hartigan dip test $p$-value $=0.05$ ).
The color opponent cells were similarly sustained (mean: $0.44 \pm$ 0.1 ) as the sustained peak of luminance cell distribution (mean $0.46 \pm 0.1$, for STi $<0.6 ; p=0.56$,).

\section{Spatial properties of color opponent cells}

We examined the spatiotemporal receptive fields of each color opponent cell. Green-OFF/UV-ON cells had strong green-OFF 
centers (Fig. 8A); contrary to expectations based on the responses to the color exchange protocol, these cells also appeared to have strong UV-OFF centers when mapped with a UV white-noise stimulus. The single green-ON/UV-OFF cell had a similarly matched STRF, with an ON center subfield for both the green and UV stimulation (Fig. 8B). This result does not match the color opponent data (see Discussion).

We placed color opponent cells in visuotopic space based on these receptive fields. Most (8/11) fell in the region of space that transitioned between UV and green $\left(\sim 0-40^{\circ}\right.$; Fig. $\left.8 C\right)$, an area of space that presumably corresponds to the opsin transition zone of the mouse retina; however, there was no significant difference in the distribution of position of opponent and nonopponent receptive fields (Student's $t$ tests comparing azimuth distributions $(p=0.88)$ and elevation distributions ( $p=0.46$ ). We also compared the variance of each distribution; the azimuth distribution of opponent cells was less variable $(p=0.02)$ than nonopponent cells, whereas the elevation distributions were not significantly different $(p=$ $0.21)$. We did not see other differences between the color opponent cells and the general population either in size (Fig. $8 D$; $5.52 \pm 2.52, p=0.46$ ) or aspect ratio (Fig. $8 E ; 0.34 \pm 0.2, p=0.36$ ).
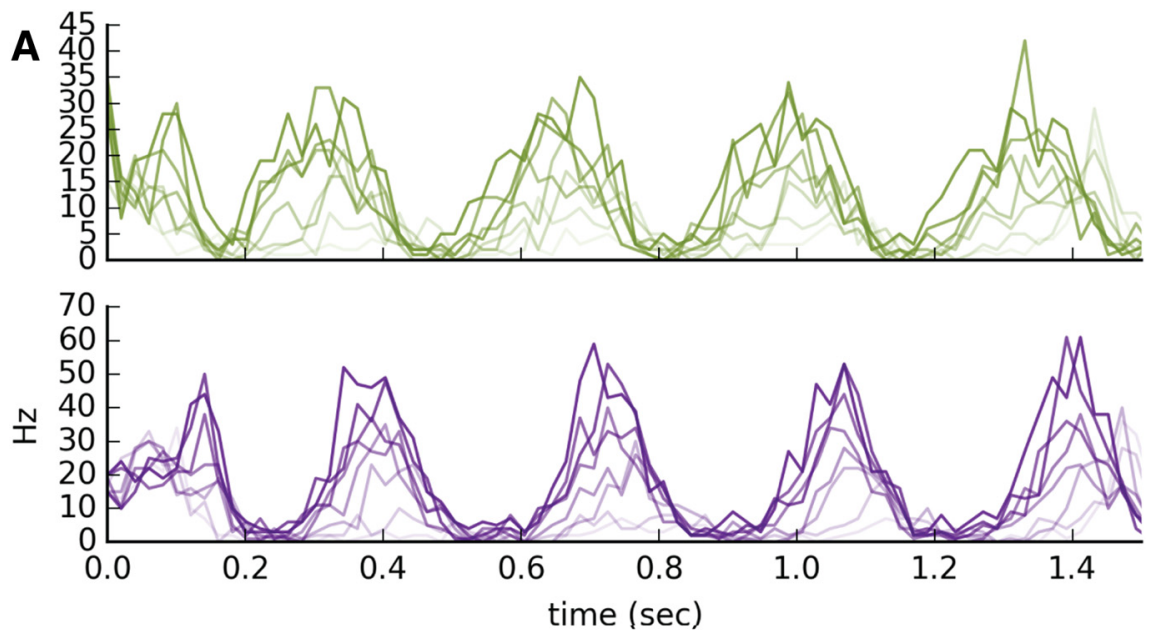

B

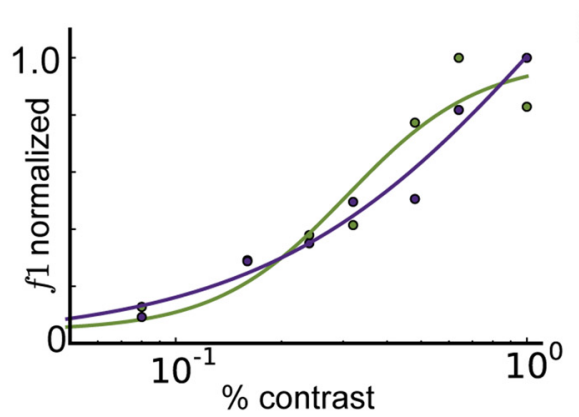

C

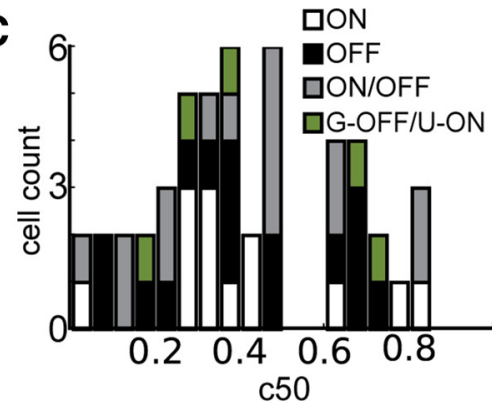

Figure 9. Contrast sensitivity of chromatic responses. $\boldsymbol{A}$, Top, Example responses to drifting gratings of increasing contrast. Response to green-only gratings in green, UV-only gratings in purple, shading indicates contrasts, with lightest at $8 \%$ and darkest at 100\%, including 16\%,24\%,32\%, 48\%, and 64\%. B, Contrast response functions from the example cell above fit with hyperbolic ratio function (solid lines). $\boldsymbol{C}$, Distribution of $c_{50}$ parameters from hyperbolic ratio function fits for cells of each color classification. Histograms are displayed as stacked histograms such that bar height shows the distribution of the total population and segments indicate the frequency for each cell type.

\section{Contrast sensitivity}

Because thalamic magnocellular and parvocellular cells in other species can be distinguished by contrast sensitivity, we also examined the relative contrast sensitivities of color opponent and luminance cells in our sample. We used a drifting-grating stimulus of fixed temporal and spatial frequency, covering 4 directions, that varied in contrast from $0 \%$ to $100 \%$ (Fig. $9 A$, top). For each cell, the $f 1$ component of the response to each contrast was used to create a CRF. CRFs were fit with a hyperbolic ratio function (Contreras and Palmer, 2003), and the $c_{50}$ of this fit taken as a measure of the contrast sensitivity (Fig. $9 A$, bottom). Fits were accepted if both the UV and green CRF had an $R^{2}$ value of $>0.25$.

We saw no difference in the contrast sensitivities of luminance cells, ON or OFF, and the group of color opponent cells (Fig. 9B; all $p>0.39$ ).

\section{Overlap of UV and green input to V1}

Finally, we examined the activity evoked by dLGN projections in V1 to UV and green stimulation. In primates, $\mathrm{L}-\mathrm{M}$ and $\mathrm{S}-(\mathrm{L}+\mathrm{M})$ have distinct cortical laminar targets (Chatterjee and Callaway, 2003) and the circuitry of dichromats is thought to be largely the same (Solomon, 2002).

We first examined UV and green luminance-evoked responses in V1 using the CSD evoked by the same brief flashes used to classify the luminance and color responses of dLGN cells. Despite some apparent differences, the structure of UV and green CSDs was similar (Fig. 10 A,B) at all retinotopic locations: initial sinks were in the middle cortical layers, defining thalamo- recipient layer $4(\mathrm{~L} 4)$; some also produced sinks deeper in layer 6 (L6, each indicated with arrows in Fig. 10B). Although there was some indication of a superficial bias of green input relative to UV, parameterizing the layer positions from each luminance change separately revealed no statistical difference in L4 sink depth (Fig. $10 C$, green: $366.2 \pm 80.2 \mu \mathrm{m}$ from pial surface; $U V: 433.8 \pm 43.0$ $\mu \mathrm{m}$ from pial surface; $p=0.18$ ). As can be seen by comparing the dynamics in Figure 10, $A$ and $B$, there were some differences in dynamics after the initial sinks. However, shifting the UV response earlier by $32 \mathrm{~ms}$ minimized the difference in the evoked activity (Fig. 10D). This difference closely matched the median difference in latency between UV and green responses in dLGN units, suggesting that the origin of the difference originates before cortex, likely in the retina.

Finally, we compared the response to luminance flashes to that of the activity evoked by luminance balanced, but color opponent, stimuli. The activity driven by simultaneous luminance changes of both colors (same sign; Fig. 10E) and/or opposing changes (opposite sign; Fig. 10F) generated cortical sinks and sources at matching depths (Fig. 10E,F). Same-sign luminance changes drove stronger and longer-lasting cortical activity, likely to increased drive to cortex from dLGN and therefore more engagement of cortical recurrent excitation. However, the initial sinks of opposite-sign stimuli were comparable to those generated by strong luminance changes. In summary, same-sign changes of both colors and opposite-sign color changes both produced L4 sinks with no significant difference in their boundaries. 


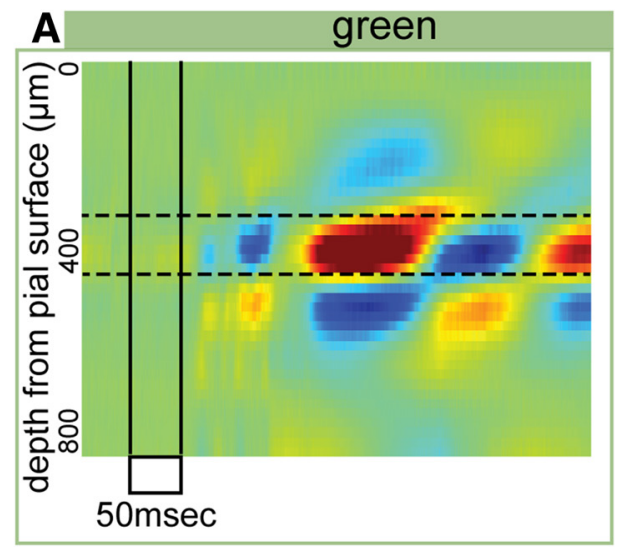

C
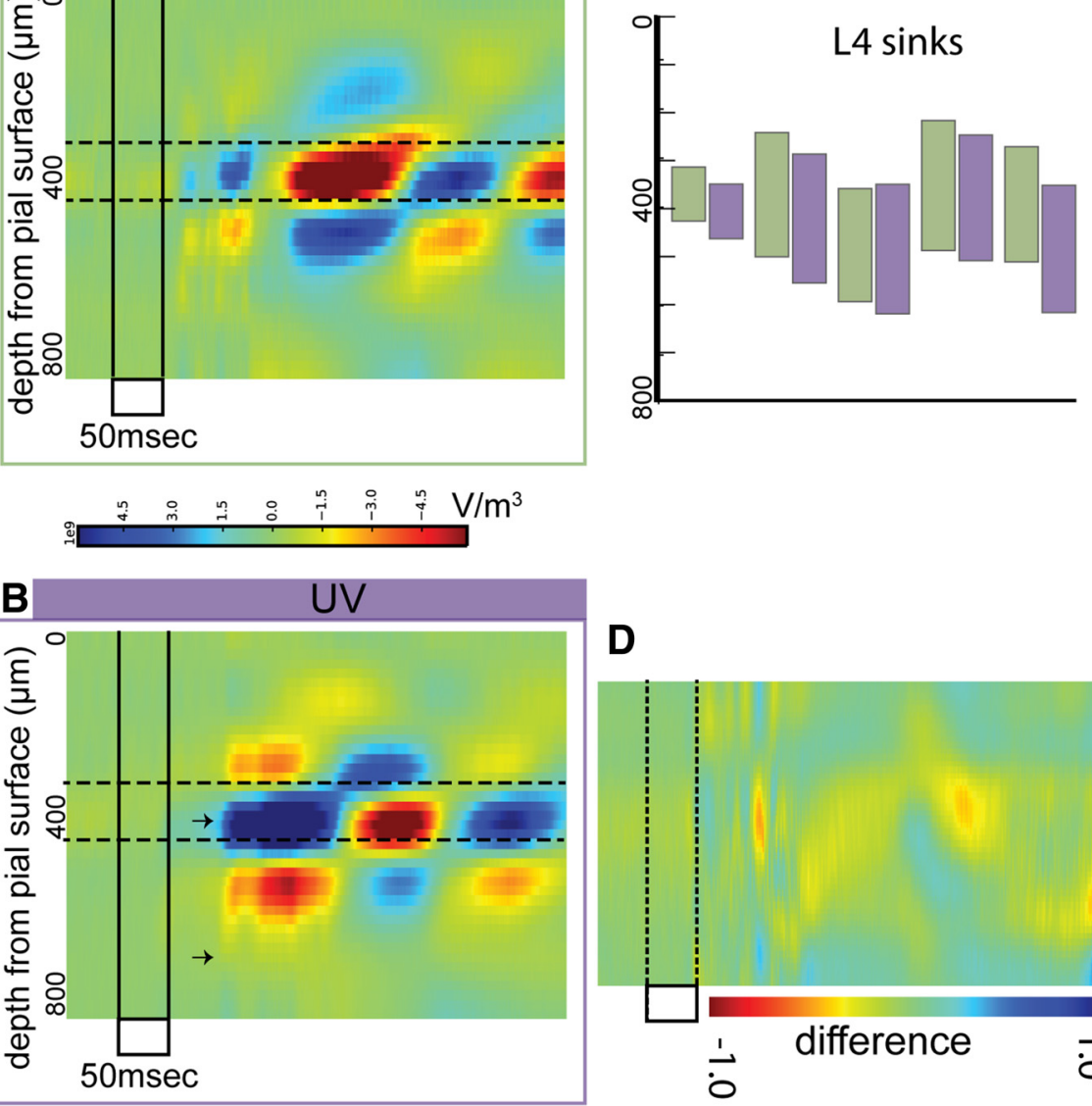

E

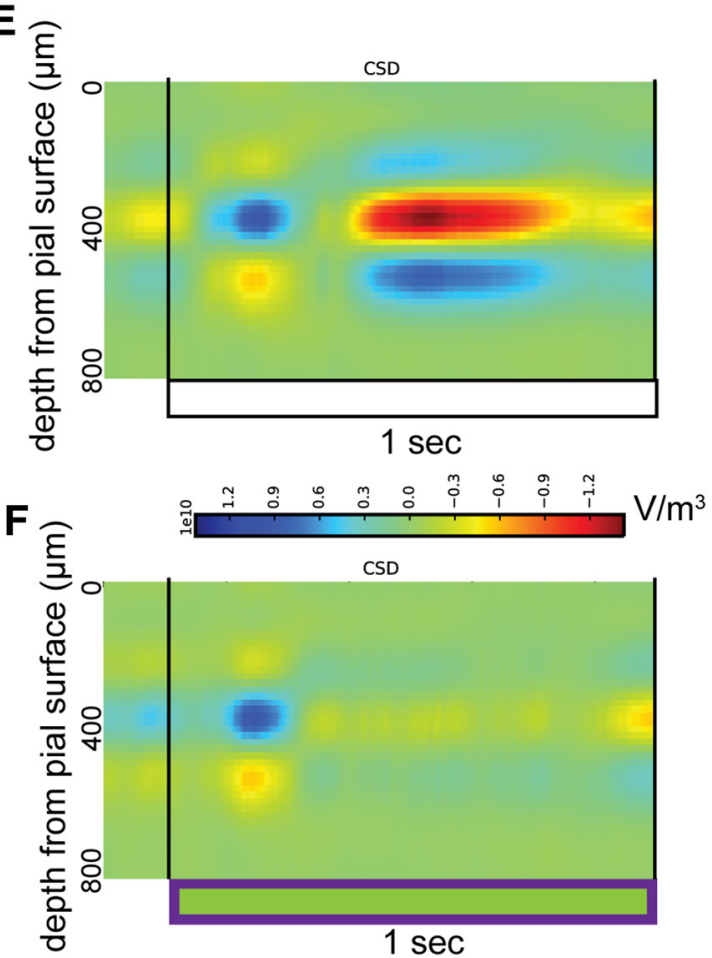

Figure 10. Laminar overlap of UV and green luminance input to V1. $A, B$, Current source density estimates from local field potentials evoked from a green-luminance-only flash $(\boldsymbol{A})$ and UV-luminance-only flash $(\boldsymbol{B})$. Layer 4 thalamo-recipient sink is annotated with a dashed line. $\boldsymbol{C}$, Boundaries of thalamic-driven sinks, presumably in $L 4$, from five separate insertions. D, Difference between UV and green CSDs after normalization for amplitude and shifting for latency difference. Color scale, -1 to 1 , is the normalized difference between green and UV CSD. E, CSD evoked by a 1 s luminance step. $F$, CSD evoked by a 1 s equiluminant color step.

\section{Discussion}

We recorded spiking responses of neurons in dLGN of awake, head-fixed mice to chromatic stimuli, finding $\mathrm{ON}$ and OFF responses driven by both opsins across visuotopic coordinates. Green responses dominated in the lower and nasal visual field and UV responses dominated in the upper visual field. We also found a subset of cells that had color opponent responses (Fig. 11A).

\section{Spatial specializations: luminance}

Anatomical and physiological results from each stage of retinal processing support the gradient of color responses across visual space that we observed in dLGN (Fig. 3). The mixed expression of opsins within cones follows a gradient across the retina, from S-opsin expression in the ventral retina to $\mathrm{M}$-opsin expression in the dorsal retina (Applebury et al., 2000; Baden et al., 2013). The distribution of each opsin is broad, such that the opsins coexpressed in the central region and expression of each extends to the opposite pole of the retina; functional responses of individual cones are even more broadly distributed.

Previous anatomical reconstructions of retinas (Dräger and Olsen, 1981; Sterratt et al., 2013) have mapped retinotopic coordinates to visual space. Combining the histological characterization of S-opsin expression with these projections predicts that the color transition zone should begin between $+7.8^{\circ}$ and $-6.0^{\circ}$ relative to the horizontal meridian, depending on azimuth. These detailed projections rely on several assumptions about mouse eye movements: using muscle insertion points as anchors to align the optical axis to $64^{\circ}$ in azimuth from the midline and $20^{\circ}$ in elevation from the horizon and maintenance of a fixed overhead binocular zone. Full visual coverage allowed us to map receptive fields in absolute visuotopic coordinates (Fig. 10A). Our physiological measurements, with a color transition zone around $0-40^{\circ}$, support the hypothesis that mouse cone distribution samples naturalistic luminance optimally (Baden et al., 2013).

Mouse $\alpha$-RGCs, which project to dLGN (Cruz-Martin et al., 2014), display nonuniformities in density and size across the retina (Bleckert et al., 2014), implying higheracuity sampling in the central parts of visual space; mouse $\alpha$-like ganglion cells can also display color opponent responses (Chang et al., 2013). We did not see an obvious difference in the size of luminance receptive fields across space (Fig. $3 C, D$ ), consistent with the idea that the retina provides dLGN and sub- 
sequent cortical targets with visual information via mixed populations of RGCs that may include $\alpha$-RGCs.

\section{Spatial specializations: color}

The expression of opsins that have sensitivity to different wavelengths does not necessarily imply the ability to discriminate stimuli of those wavelengths. In most mammals, cone-specific bipolar cell (BC) pathways propagate pure opsin signals: primates have both S-ON and S-OFF pathways (Dacey and Lee, 1994; Dacey and Packer, 2003), ground squirrels have at least a S-ON BC pathway ( $\mathrm{Li}$ and $\mathrm{DeVr}$ ies, 2006), and rabbits have both S-ON and S-OFF pathways (Mills et al., 2014). RGCs combine these into S-ON/M-OFF and $\mathrm{S}-\mathrm{OFF} / \mathrm{M}-\mathrm{ON}$ channels. In mice, widespread coexpression of both opsins in the same cone (Applebury et al., 2000; Baden et al., 2013) considerably complicates this scenario. The extent of mixing is a complex topic, but some opsin-specific signal is preserved in the mouse retina. As measured by expression, $\sim 4 \%$ of cones express only S-opsin and individual cones tend to be functionally more biased toward one opsin than expression alone would indicate (Baden et al., 2013).

Importantly, there is behavioral evidence that mice can access luminanceindependent chromatic information (Jacobs et al., 2004). Retinal evidence supports the existence of a color opponent pathway, at least in some parts of the mouse retina. Type 9 BCs, which make up $2 \%$ of the bipolar cell population, contact pure Scones exclusively (Haverkamp et al., 2005) and display an S-ON functional response. Another BC, type 1, shows green-OFF responses (Breuninger et al., 2011). At the RGC level, some " $\alpha$-like" ganglion cells in the opsin transition zone show S-M opponent responses (Chang et al., 2013). More recent work also identifies several RGC types, including "non- $\alpha$-type" cells that have green-ON/UV-OFF responses (Baden et al., 2016). In JAM-B RGCs, this type of opponency is created by a rod-cone opponency (Joesch and Meister, 2016), although the intensities used here $\left(\sim 8 \times 10^{4}\right.$ $\mathrm{R}^{\star} / \mathrm{s}$ ) prevented us from observing such rod-driven surrounds. In another species with a gradient of $\mathrm{S}$ - and $\mathrm{M}$-opsins, guinea pig, rare (1\%) color opponent ganglion cells, S-ON/M-OFF and S-OFF/MON, have also been reported (Yin et al., 2006; Yin et al., 2009).

Similar to the proportions of bipolar cells in the retina, we observed few color opponent cells $(\sim 10 \%)$ relative to luminance cells. Within color opponent cells, the majority (11/12) were green-OFF/UV-ON, with only a single example of a green-ON/ $\mathrm{UV}-\mathrm{OFF}$; this is again consistent with the presence of green-OFF and UV-ON channels at the bipolar cell level. The spatial distribution, especially the lack of opponent cells in the lower retina where pure $\mathrm{S}$ - and $\mathrm{M}$-cones can be found, suggests that these cells receive input from RGCs that compare the input from $\mathrm{M}$-cones with differing ratios of $\mathrm{M}$ - and S-opsin expression, as schematized in Figure 11. The opponent responses of $\alpha$-like cells in the mouse retina (Chang et al., 2013) suggests that these cells may provide input to the color opponent cells observed here.

\section{Comparison with S-M pathways in other mammals}

We have noted similarities of the mouse retinal color systems to those of dichromats such as ground squirrels and guinea pigs and to trichromatic primates. Several differences between the S-M opponency that we observed here and the S-M (in dichromats) and $\mathrm{S}-(\mathrm{L}+\mathrm{M})$ (in trichromats) pathways should be noted. A major difference is the reduction in the overlap between the sensitivities of the opsins because of the S-shift to UV wavelengths. In addition, mixing of both opsins in the M-cone may further dilute luminance-independent wavelength signals.

The cells in our population that display opponent responses to chromatically mixed stimuli show the same sign responses when examined under monochromatic conditions (Fig. 8). This type of color opponent response from a cell with same-sign cone input has also been observed in macaque V1 (Johnson et al., 2004). How could a cell with an OFF-type STRF to both UV and green produce color opponent response? One explanation relies on color adaptation at the level of cones: a given opponent dLGN cell receives input from an $\alpha$-RGC that sums the input of bipolar cell pathways that have mixed opsin input of the same sign (Chang et al., 2013), but opposing weights of green and UV in center and 
surround. Such responses are schematized in Figure 11B. Under monochromatic conditions, color adaptation at the level of cone inputs balances the strength of center and surround input and results in OFF type responses; under conditions in which cones have more balanced UV and green gains, asymmetries in the center and surround create broad color opponency. Another possible explanation is global adaptation to mean luminance differences between the color opponent stimulus and the monochromatic noise stimuli: strong luminance adaptation can change sign of response in RGCs (Pearson and Kerschensteiner, 2015). In the present work, we mapped receptive fields with monochromatic noise; it is possible that revealing spatial opponency in the mouse requires conditions in which the S- and $\mathrm{M}$-opsin gain mechanisms are balanced.

\section{Mouse pathways to V1}

Color versus luminance responses are useful for interpreting dLGN neurons as contributing to parallel pathways in the primate visual system (Nassi and Callaway, 2009). Blue-yellow opponent cells are a hallmark of the primate koniocellular pathway (Hendry and Reid, 2000). Conduction velocity and nonlinearity of spatial summation indicate that at least two similar parallel pathways exist in mouse dLGN (White et al., 1998; Grubb and Thompson, 2003; Denman and Contreras, 2016). Can we use color opponency to help define pathways in mouse dLGN or does this happen by chance from sampling of a luminance pathway that has a sharp transition (Chang et al., 2013)? Given the spatial distribution and frequency of the UV-green opponent cells that we observed, we do not think the opponent cells that we observed are homologous mouse dLGN koniocellular pathway cells. Rather we see them as a luminance pathway that samples an asymmetrical distribution of cones; whereas we do not know the ganglion or bipolar cell inputs to our LGN cells, it has been demonstrated previously that many mouse bipolar cell types indiscriminately contact S- and M-cones (Breuninger et al., 2011).

Given that mice appear to have behavioral access to wavelength information (Jacobs et al., 2004), downstream targets may be able to extract color information efficiently from the few color opponent dLGN cells in the color transition zone. Alternatively, color opponent signals could be created more centrally from color-biased cells in dLGN; indeed, spatially color opponent responses were recently reported in mouse V1 (Tan et al., 2015).

\section{Notes}

Supplemental material for this article is available at https://github.com/ danieljdenman/mouse_chromatic/. The repository contains Jupyter notebook and Python functions sufficient to reproduce data analysis and figures. This material has not been peer reviewed.

\section{References}

Applebury ML, Antoch MP, Baxter LC, Chun LL, Falk JD, Farhangfar F, Kage K, Krzystolik MG, Lyass LA, Robbins JT (2000) The murine cone photoreceptor: a single cone type expresses both $\mathrm{S}$ and $\mathrm{M}$-opsins with retinal spatial patterning. Neuron 27:513-523. CrossRef Medline

Baden T, Schubert T, Chang L, Wei T, Zaichuk M, Wissinger B, Euler T (2013) A tale of two retinal domains: near-optimal sampling of achromatic contrasts in natural scenes through asymmetric photoreceptor distribution. Neuron 80:1206-1217. CrossRef Medline

Baden T, Berens P, Franke K, Román Rosón M, Bethge M, Euler T (2016) The functional diversity of retinal ganglion cells in the mouse. Nature 529:345-350. CrossRef Medline

Bleckert A, Schwartz GW, Turner MH, Rieke F, Wong RO (2014) Visual space is represented by nonmatching topographies of distinct mouse retinal ganglion cell types. Curr Biol 24:310-315. CrossRef Medline

Breuninger T, Puller C, Haverkamp S, Euler T (2011) Chromatic bipolar cell pathways in the mouse retina. J Neurosci 31:6504-6517. CrossRef Medline

Carcieri SM, Jacobs AL, Nirenberg S (2003) Classification of retinal ganglion cells: a statistical approach. J Neurophysiol 90:1704-1713. CrossRef Medline

Chang L, Breuninger T, Euler T (2013) Chromatic coding from cone-type unselective circuits in the mouse retina. Neuron 77:559-571. CrossRef Medline

Chatterjee S, Callaway EM (2003) Parallel colour-opponent pathways to primary visual cortex. Nature 426:668-671. CrossRef Medline

Contreras D, Palmer L (2003) Response to contrast of electrophysiologically defined cell classes in primary visual cortex. J Neurosci 23:6936-6945. Medline

Cruz-Martin A, El-Danaf RN, Osakada F, Sriram B, Dhande OS, Nguyen PL, Callaway EM, Ghosh A, Huberman AD (2014) A dedicated circuit links direction-selective retinal ganglion cells to the primary visual cortex. $\mathrm{Na}$ ture 507:358-361. CrossRef Medline

Dacey DM, Lee BB (1994) The 'blue-on' opponent pathway in primate retina originates from a distinct bistratified ganglion cell type. Nature 367: 731-735. CrossRef Medline

Dacey DM, Packer OS (2003) Colour coding in the primate retina: diverse cell types and cone-specific circuitry. Curr Opin Neurobiol 13:421-427. Medline

Denman DJ, Contreras D (2016) On parallel streams through the mouse dorsal lateral geniculate nucleus. Front Neural Circuits 10:20. CrossRef Medline

Dräger UC, Olsen JF (1981) Ganglion cell distribution in the retina of the mouse. Invest Ophthalmol Vis Sci 20:285-293.

Grubb MS, Thompson ID (2003) Quantitative characterization of visual response properties in the mouse dorsal lateral geniculate nucleus. J Neurophysiol 90:3594-3607. CrossRef Medline

Haverkamp S, Wässle H, Duebel J, Kuner T, Augustine GJ, Feng G, Euler T (2005) The primordial, blue-cone color system of the mouse retina. J Neurosci 25:5438-5445. CrossRef Medline

Hendry SH, Reid RC (2000) The koniocellular pathway in primate vision. Annu Rev Neurosci 23:127-153. CrossRef Medline

Henriksson JT, Bergmanson JP, Walsh JE (2010) Ultraviolet radiation transmittance of the mouse eye and its individual media components. Exp Eye Res 90:382-387. CrossRef Medline

Jacobs GH, Williams GA (2007) Contributions of the mouse UV photopigment to the ERG and to vision. Doc Ophthamol 115:137-144. CrossRef Medline

Jacobs GH, Neitz J, Deegan JF 2nd (1991) Retinal receptors in rodents maximally sensitive to ultraviolet light. Nature 353:655-656. CrossRef Medline

Jacobs GH, Williams GA, Fenwick JA (2004) Influence of cone pigment coexpression on spectral sensitivity and color vision in the mouse. Vision Res 44:1615-1622. CrossRef Medline

Joesch M, Meister M (2016) A neuronal circuit for colour vision based on rod-cone opponency. Nature 532:236-239. CrossRef Medline

Johnson EN, Hawken MJ, Shapley R (2004) Cone inputs in macaque primary visual cortex. J Neurophysiol 91:2501-2514. CrossRef Medline

Jones JP, Palmer LA (1987) The 2D spatial structure of simple receptive fields in cat striate cortex. J Neurophysiol 58:1187-1211. Medline

Lee BB, Martin PR, Valberg A (1989) Nonlinear summation of M- and $\mathrm{L}$-cone inputs to phasic retinal ganglion cells of the macaque. J Neurosci 9:1433-1442. Medline

Li W, DeVries SH (2006) Bipolar cell pathways for color and luminance vision in a dichromatic mammalian retina. Nat Neurosci 9:669-675. Medline

Lopez CM, MItra S, Putzeys J, Raducanu B, Ballini M, Adrei A, Severi S, Welkenhuysen M, Van Hoof C, Musa S, Yazicioglul RF (2016) A 966electrode neural probe with 384 configurable channels in $0.13 \mu \mathrm{m}$ SOI CMOS. ISSCC Extended Abstracts, 22.7. ieeexplore.ieee.org/iel7/ 7405163/7417881/07418072.pdf.

Lyubarsky AL, Falsini B, Pennesi ME, Valentini P, Pugh EN Jr (1999) UVand midwave-sensitive cone-driven retinal responses of the mouse: a possible phenotype for coexpression of cone photopigments. J Neurosci 19: 442-455. Medline

Mills SL, Tian LM, Hoshi H, Whitaker CM, Massey SC (2014) Three distinct blue-green color pathways in a mammalian retina. J Neurosci 34:17601768. CrossRef Medline 
Nassi JJ, Callaway EM (2009) Parallel processing strategies of the primate visual system. Nat Rev Neurosci 10:360-372. CrossRef Medline

Pearson JT, Kerschensteiner D (2015) Ambient illumination switches contrast preference of specific retinal processing streams. J Neurophysiol 114:540-550. CrossRef Medline

Pettersen KH, Devor A, Ulbert I, Dale AM, Einevoll GT (2006) Currentsource density estimation based on inversion of electrostatic forward solution: effects of finite extent of neuronal activity and conductivity discontinuities. J Neurosci Methods 154:116-133. CrossRef Medline

Reid RC, Shapley RM (2002) Space and time maps of cone photoreceptor signals in macaque lateral geniculate nucleus. J Neurosci 22:6158-6175. Medline

Rodriguez A, Laio A (2014) Machine learning: clustering by fast search and find of density peaks. Science 344:1492-1496. CrossRef Medline

Roorda A, Williams DR (1999) The arrangement of the three cone classes in the living human eye. Nature 397:520-522. CrossRef Medline

Shapley R, Hawken M (2002) Neural mechanisms for color perception in the primary visual cortex. Curr Opin Neurobiol 12:426-432. CrossRef Medline

Solomon SG (2002) Striate cortex in dichromatic and trichromatic marmosets: Neurochemical compartmentalization and geniculate input. J Comp Neurol 450:366-381. CrossRef Medline

Sterratt DC, Lyngholm D, Dillshaw DJ, Thompson ID (2013) Standard anatomical and visual space for the mouse retina: computational reconstruction and transformation of flattened retinae with the retistruct package. PLoS Comp Biol 9:e1002921. CrossRef Medline
Tan Z, Sun W, Chen TW, Kim D, Ji N (2015) Neuronal representation of ultraviolet visual stimuli in mouse primary visual cortex. Sci Rep 5:12597. CrossRef Medline

Teeters JL et al. (2015) Neurodata without borders: creating a common data format for neurophysiology. Neuron 88:629-634. CrossRef Medline

Wallace DJ, Greenberg DS, Sawinski J, Rulla S, Notaro G, Kerr JN (2013) Rats maintain an overhead binocular field at the expense of constant fusion. Nature 498:65-69. CrossRef Medline

Wang YV, Weick M, Demb JB (2011) Spectral and temporal sensitivity of cone-mediated responses in mouse retinal ganglion cells. J Neurosci 31: 7670-7681. CrossRef Medline

White AJ, Wilder HD, Goodchild AK, Sefton AJ, Martin PR (1998) Segregation of receptive field properties in the lateral geniculate nucleus of a New-World monkey, the marmoset Callithrix jacchus. J Neurophysiol 80:2063-2076. Medline

Yger P, Spampinato GLB, Esposito E, Lefebvre B, Deny S, Gardella C, Stimberg M, Jetter F, Zeck G, Picaud S, Duebel J, Marre O (2016) Fast and accurate spike sorting in vitro and in vivo for up to thousands of electrodes. bioRxiv doi: 10.1101/067843.

Yin L, Smith RG, Sterling P, Brainard DH (2006) Chromatic properties of horizontal and ganglion cell responses follow a dual gradient in cone opsin expression. J Neurosci 26:12351-12361. CrossRef Medline

Yin L, Smith RG, Sterling P, Brainard DH (2009) Physiology and morphology of color opponent ganglion cells in a retina expressing a dual gradient of S and M-opsins. J Neurosci 29:2706-2724. CrossRef Medline 